\title{
Regional severe particle pollution and its association with synoptic weather patterns in the Yangtze River Delta region, China
}

\author{
Lei Shu ${ }^{1}$, Min Xie ${ }^{1}$, Da Gao ${ }^{1}$, Tijian Wang ${ }^{1}$, Dexian Fang ${ }^{2}$, Qian Liu ${ }^{3}$, Anning Huang ${ }^{1}$, and Liwen Peng ${ }^{1}$ \\ ${ }^{1}$ School of Atmospheric Sciences, CMA-NJU Joint Laboratory for Climate Prediction Studies, Jiangsu Collaborative \\ Innovation Center for Climate Change, Nanjing University, Nanjing 210023, China \\ ${ }^{2}$ Chongqing Institute of Meteorology and Science, Chongqing 401147, China \\ ${ }^{3}$ Jiangsu Provincial Academy of Environmental Science, Nanjing 210036, China
}

Correspondence to: Min Xie (minxie@nju.edu.cn) and Tijian Wang (tjwang@nju.edu.cn)

Received: 18 May 2017 - Discussion started: 2 June 2017

Revised: 12 September 2017 - Accepted: 24 September 2017 - Published: 1 November 2017

\begin{abstract}
Regional air pollution is significantly associated with dominant weather systems. In this study, the relationship between the particle pollution over the Yangtze River Delta (YRD) region and weather patterns is investigated. First, the pollution characteristics of particles in the YRD are studied using in situ monitoring data $\left(\mathrm{PM}_{2.5}\right.$ and $\left.\mathrm{PM}_{10}\right)$ in 16 cities and Terra/MODIS AOD (aerosol optical depth) products collected from December 2013 to November 2014. The results show that the regional mean value of AOD is high in the YRD, with an annual mean value of $0.71 \pm 0.57$. The annual mean particle concentrations in the cities of Jiangsu Province all exceed the national air quality standard. The pollution level is higher in inland areas, and the highest concentrations of $\mathrm{PM}_{2.5}$ and $\mathrm{PM}_{10}$ are 79 and $130 \mu \mathrm{g} \mathrm{m}^{-3}$, respectively, in Nanjing. The $\mathrm{PM}_{2.5}: \mathrm{PM}_{10}$ ratios are typically high, thus indicating that $\mathrm{PM}_{2.5}$ is the overwhelmingly dominant particle pollutant in the YRD. The wintertime peak of particle concentrations is tightly linked to the increased emissions during the heating season as well as adverse meteorological conditions. Second, based on NCEP (National Center for Environmental Prediction) reanalysis data, synoptic weather classification is conducted and five typical synoptic patterns are objectively identified. Finally, the synthetic analysis of meteorological fields and backward trajectories are applied to further clarify how these patterns impact particle concentrations. It is demonstrated that air pollution is more or less influenced by high-pressure systems. The relative position of the YRD to the anti-cyclonic circulation exerts significant effects on the air quality of the YRD. The YRD is largely influenced by polluted air masses from the northern and the
\end{abstract}

southern inland areas when it is located at the rear of the East Asian major trough. The significant downward motion of air masses results in stable weather conditions, thereby hindering the diffusion of air pollutants. Thus, this pattern is quite favorable for the accumulation of pollutants in the YRD, resulting in higher regional mean $\mathrm{PM}_{10}\left(116.5 \pm 66.9 \mu \mathrm{g} \mathrm{m}^{-3}\right)$, $\mathrm{PM}_{2.5}\left(75.9 \pm 49.9 \mu \mathrm{g} \mathrm{m}^{-3}\right)$, and AOD (0.74) values. Moreover, this pattern is also responsible for the occurrence of most large-scale regional $\mathrm{PM}_{2.5}(70.4 \%)$ and $\mathrm{PM}_{10}(78.3 \%)$ pollution episodes. High wind speed and clean marine air masses may also play important roles in the mitigation of pollution in the YRD. Especially when the clean marine air masses account for a large proportion of all trajectories (i.e., when the YRD is affected by the cyclonic system or oceanic circulation), the air in the YRD has a lesser chance of being polluted. The observed correlation between weather patterns and particle pollution can provide valuable insight into making decisions about pollution control and mitigation strategies.

\section{Introduction}

The common occurrence of regional particle pollution has acquired worldwide attention in the scientific community (Malm et al., 1994; Putaud et al., 2004; Chan and Yao, 2008) due to its adverse impacts on visibility (Singh and Dey, 2012; Green et al., 2012) and public health (Kappos et al., 2004; Brook et al., 2010). Generally, the causes of this kind of pollution involve diverse aspects. Two major contributors to this 
pollution include the emission of pollutants and weather conditions (Oanh and Leelasakultum, 2011; Young et al., 2016). Particle pollution in urban agglomerations is primarily attributed to very large amounts of the anthropogenic emissions of primary particles and their precursors (e.g., $\mathrm{SO}_{2}$, $\mathrm{NO}_{x}$, VOCs). However, these emissions are normally quasistable within a certain period of time (Kurokawa et al., 2013). Thus, the pollution level in a certain region generally depends on the regional weather conditions (namely, weather patterns), which are strongly correlated with synoptic-scale atmospheric circulation (Buchanan et al., 2002; Chuang et al., 2008; Flocas et al., 2009; Zhang et al., 2012; Zhao et al., 2013; Russo et al., 2014; Grundstrom et al., 2015; Zheng et al., 2015a, b; Li et al., 2016).

To date, researchers have gained an improved knowledge of the relationship between weather patterns and particle pollution. For example, Buchanan et al. (2002) observed significantly elevated concentrations of black smoke and $\mathrm{PM}_{10}$ under the anti-cyclonic, southerly and southeasterly weather types in the city of Edinburgh in the UK between 1981 and 1996. Russo et al. (2014) presented an objective classification scheme for the atmospheric circulation affecting Portugal between 2002 and 2010 and revealed that higher concentrations of $\mathrm{PM}_{10}, \mathrm{O}_{3}$, and $\mathrm{NO}_{2}$ are predominantly associated with synoptic circulation that is characterized by an eastern component and the advection of dry air masses. Previous studies have confirmed that different levels of air pollution are closely related with weather patterns, and they ascribed its great spatial variability to the fact that the dominant weather pattern differs between different regions (Flocas et al., 2009; Grundstrom et al., 2015).

In recent decades, the air pollution caused by $\mathrm{PM}_{10}$ and $\mathrm{PM}_{2.5}$ has become an extremely prominent air quality problem in the urban areas of China (Deng et al., 2011; Huang et al., 2012, 2014; Ji et al., 2012; Cheng et al., 2013; Kang et al., 2013; Zhang et al., 2014; Xie et al., 2016a, c; Zhu et al., 2017). Many studies have tried to reveal the meteorological contributions to these severe particle pollution episodes. Chuang et al. (2008) identified seven weather patterns for aerosol events occurring from March 2002 to February 2005 in the Taipei Basin and suggested that weather systems and their associated terrain blocking played important roles in the accumulation of $\mathrm{PM}_{2.5}$ during the days of events. Niu et al. (2010) revealed the potential impacts of the weakening of the East Asian monsoon circulation and increased aerosol loading on the increase in wintertime fog in China. Zhao et al. (2013) analyzed a regional haze episode in the North China Plain from 16 to 19 January 2010 and noted that strong temperature inversion, weak surface wind speed, and descending air motions in the boundary layer were responsible for the accumulation of pollutants in a shallow layer that produced high pollutant concentrations within the source region. Zheng et al. (2015a) found that favorable atmospheric circulation conditions are responsible for the severe winter haze over northeastern China. Li et al. (2016) noted that the fog- haze days over central and eastern China exhibited the clear features of interannual variations and that the strong (weak) East Asian winter monsoon may result in less (more) foghaze days throughout this region.

The Yangtze River Delta (YRD) region, which is located in the southeastern coastal area of East China, is one of the most developed urban economic regions in the world; it generally includes Shanghai, Jiangsu Province and Zhejiang Province, and it occupies over $20 \%$ of China's total gross domestic product (Shu et al., 2016; Xie et al., 2016a, 2017). In recent years, similar to other megacity clusters in China, such as the Beijing-Tianjin-Hebei (BTH) region (He et al., 2001; Chan and Yao, 2008; Ji et al., 2012; Zhang et al., 2012, 2014; Zhao et al., 2013; Zheng et al., 2015a) and the Pearl River Delta (PRD) region (Ho et al., 2003; Chan and Yao, 2008; Xie et al., 2016c; Zhu et al., 2017), the YRD has suffered from severe air pollution problems caused by an increasing population, urban expansion, and industrialization (Chan and Yao, 2008; Fu et al., 2008, 2010, 2014; Deng et al., 2011; Li et al., 2011; Huang et al., 2012; Kang et al., 2013; Wang et al., 2013, 2014, 2015; Xie et al., 2014, 2016a, b, 2017; Feng et al., 2015; Zheng et al., 2015b; Shu et al., 2016; Xu et al., 2016; Ming et al., 2017). In particular, severe particle pollution episodes are widely recognized as one of the major air pollution issues in the YRD (Fu et al., 2008, 2010; Deng et al., 2011; Huang et al., 2012; Kang et al., 2013; Kong et al., 2013; Wang et al., 2013, 2014, 2015; Fu et al., 2014; Feng et al., 2015; Zheng et al., 2015b; Xu et al., 2016; Ming et al., 2017). Thus, many studies have been conducted to determine the contamination status (Fu et al., 2010; Kang et al., 2013; Wang et al., 2013, 2015; Feng et al., 2015; Ming et al., 2017), possible source (Fu et al., 2010, 2014; Kong et al., 2013; Wang et al., 2013, 2014; Xu et al., 2016), and causes or features (Fu et al., 2008, 2010; Huang et al., 2012; Wang et al., 2015; Zheng et al., 2015a) of these episodes. However, studies that have attempted to determine how particle pollution in the YRD is associated with synoptic weather patterns are still quite limited. Zheng et al. (2015b) summarized the synoptic-scale atmospheric circulations influencing the distribution of particles over eastern China during autumn from 2001 to 2010. They found that there are six polluted weather types and three clean ones and revealed that heavy pollution events most commonly occur when the study areas are located at the rear of the anticyclone. However, their study considered the influence of pollution in a region that is larger than the YRD, only focused on pollution in October, and was mainly based on satellite aerosol optical depth (AOD) data. Ground-based monitoring particle concentration data can better represent the status of particle pollution in the urban atmosphere of the YRD. Thus, to better understand the relationship between pollution in the planetary boundary layer and the synoptic weather patterns over the YRD, further studies should be conducted based on surface monitoring data collected over a time period of at least 1 year in the YRD. 


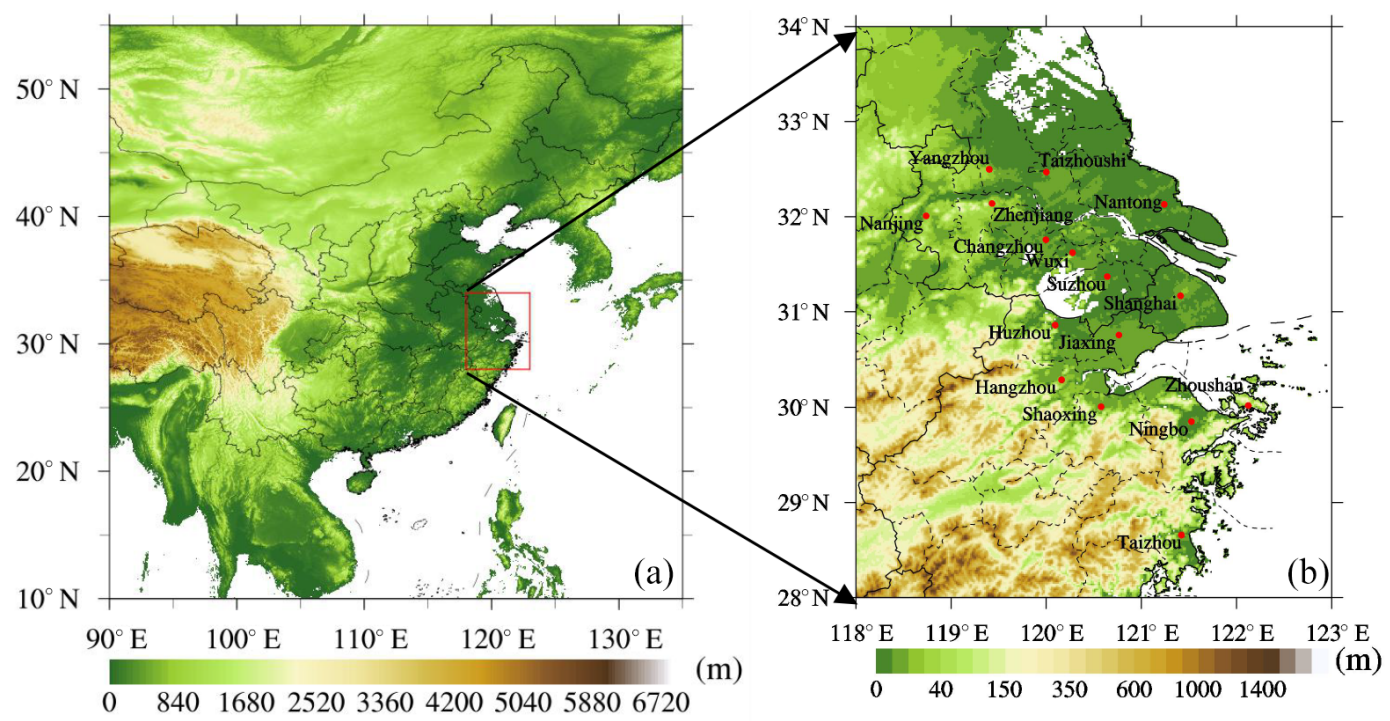

Figure 1. The location of the YRD in China (a) and 16 typical cities in the YRD (b), with terrain elevation data. The terrain elevation data are obtained from the website (https://www.ngdc.noaa.gov/mgg/global/relief/ETOPO1/data/bedrock/cell_registered/).

This work attempts to enhance our understanding of particle pollution in the YRD and provide scientific knowledge about the association of regional severe particle pollution and synoptic weather patterns. First, we analyze the spatial and temporal distribution of $\mathrm{PM}_{10}, \mathrm{PM}_{2.5}$, and $\mathrm{AOD}$ in the YRD from December 2013 to November 2014 to illustrate the characteristics of particle pollution over this region. Second, synoptic weather classification is conducted to reveal the weather patterns related to heavy pollution. Finally, the synthetic analyses of meteorological fields and backward trajectories are used to further clarify the impact mechanism. In this paper, Sect. 2 describes the observed data, the synoptic weather classification method, and the trajectory model. Section 3 presents our main findings, including a detailed analysis of the characteristics of particle pollution in the YRD, the synoptic weather patterns affecting this pollution, and the mechanism by which weather systems impact pollution. Finally, a brief summary is presented in Sect. 4 .

\section{Data and methods}

\subsection{Observed data}

The observed air quality data used in this study are obtained from the National Environmental Monitoring Center (NEMC) of China. The in situ monitoring data of the hourly concentrations of $\mathrm{PM}_{2.5}, \mathrm{PM}_{10}, \mathrm{CO}, \mathrm{NO}_{2}, \mathrm{SO}_{2}$, and $\mathrm{O}_{3}$ are acquired from the national air quality real-time publishing platform (http://106.37.208.233:20035). Sixteen cities are selected as representative research sites to better reflect the status of particle pollution over the YRD region. These cities include Shanghai, Changzhou, Nanjing,
Nantong, Suzhou, Taizhoushi, Wuxi, Yangzhou, Zhenjiang, Hangzhou, Huzhou, Jiaxing, Ningbo, Shaoxing, Taizhou, and Zhoushan (here, Taizhou in Jiangsu Province is referred to as Taizhoushi to distinguish it from the city of Taizhou in Zhejiang Province). Figure 1 shows the locations of the 16 cities in the YRD. In order to better characterize the pollution levels of each city, the hourly pollutant concentration of each city is calculated as the average value of the pollutant concentrations measured in several of the national monitoring sites in that city. The sampling methods and the quality assurance and quality control (QA/QC) procedures used at each site are in accordance with the Chinese national standard HJ/T193-2005 (State Environmental Protection Administration of China, 2006; Xie et al., 2016b). Furthermore, manual inspection is conducted during data processing; this inspection includes the removal of missing and abnormal values (e.g., $\mathrm{PM}_{2.5}$ values that are higher than $\mathrm{PM}_{10}$ values). The study period lasts from December 2013 to November 2014. In the following analysis, winter refers to the period from December 2013 to February 2014. Accordingly, spring, summer, and autumn represent the periods from March to May, June to August, and September to November 2014, respectively.

The use of Moderate Resolution Imaging Spectroradiometer (MODIS) aerosol products can help us comprehensively analyze the spatial and temporal variations in aerosol loading over China. In this study, we use the AOD data obtained at a wavelength of $550 \mathrm{~nm}$ in the Terra/MODIS daily global Level 3 products (MOD08_D3). These data can be obtained from the MODIS collection 6 (C6) dataset (https: //ladsweb.modaps.eosdis.nasa.gov/search/). MODIS aerosol products are derived using two entirely independent retrieval algorithms: one is used for deriving aerosols over land (Chu 
et al., 2002, 2003) and another is used for deriving aerosols over the ocean (Remer et al., 2002, 2005; Chu et al., 2005). Here, we use the C6 Deep Blue (DB) products to derive aerosols over land, with a spatial resolution of $1^{\circ} \times 1^{\circ}$, during the period from December 2013 to November 2014. For detailed descriptions of the retrieval algorithms and their accuracy and validation, refer to the work of Hsu et al. (2013).

To illustrate actual weather situations, the hourly monitored meteorological parameter records in each of the 16 typical cities are also applied. These data include $2 \mathrm{~m}$ temperature $(T), 2 \mathrm{~m}$ relative humidity $(\mathrm{RH}), 10 \mathrm{~m}$ wind speed (WS), $10 \mathrm{~m}$ wind direction (WD) and surface air pressure $(P)$. These data are collected from the National Meteorological Center (http://www.nmc.cn).

\subsection{Synoptic weather classification}

Synoptic weather classification refers to the analysis of historical weather charts and the characterization of weather systems. It is more effective for producing disastrous weather forecasts due to its ability to reveal atmospheric circulation situations. With the gradual popularization of computer analysis and the increased sharing of data, synoptic weather classification has great practical value in a wide variety of research fields. For example, it has widespread applications in the field of analyzing weather patterns related to air pollution (Mcgregor and Bamzelis, 1995; Zhang et al., 2012; Santurtún et al., 2015).

Methods of synoptic weather classification can generally be divided into objective and subjective methods (El-Kadi and Simithson, 1992). In this study, we apply the sumsof-squares technique, which is an objective classification method that was established in 1973 by Kirchhofer (1973). The sums-of-squares technique can effectively categorize more than $90 \%$ of analyzed weather maps, which represents an improvement over other correlation techniques (Yarnal, 1984). The application of this technique involves three steps. First, the daily pressure data at each grid point are normalized as follows:

$Z_{i}=\frac{\left(X_{i}-\bar{X}\right)}{\mathrm{SD}}$,

where $Z_{i}$ is the normalized value of grid point $i, X_{i}$ is the value at grid point $i, \bar{X}$ is the mean value of the study domain, and SD is the standard deviation. Data normalization removes the effects of the magnitude of pressure and improves the seasonal comparability of different weather types. Second, each normalized grid point is compared to all other grid points based on the Kirchhofer score $(S)$ of each grid point:

$S=\sum_{i=1}^{N}\left(Z_{a i}-Z_{b i}\right)$,

where $Z_{a i}$ is the normalized value of grid point $i$ on day $a$, $Z_{b i}$ is the normalized value of grid point $i$ on day $b$, and $N$ is the number of grid points. The Kirchhofer score $(S)$ is calculated for each row (denoted as $S_{\mathrm{R}}$ ), each column $\left(S_{\mathrm{C}}\right)$, and the entire study domain $\left(S_{\mathrm{T}}\right)$ to ensure the pattern similarity between any pair of patterns for all grid points. Finally, all days are separated into one of the identified synoptic weather patterns based on these three values and their empirically derived thresholds. Thus, the values of $S_{\mathrm{R}}, S_{\mathrm{C}}$, and $S_{\mathrm{T}}$ must be lower than their respective threshold values for these patterns to be accepted as similar (Barry et al., 1981). For each daily grid, the lowest significant Kirchhofer score $(S)$ is recorded with the associated key day, thus denoting the synoptic type of that day. All remaining days are considered to be "unclassified".

The meteorological field dataset used in the sums-ofsquares technique contains NCEP-DOE AMIP-II Reanalysis (R-2) data (Kanamitsu et al., 2002), which are collected at 00:00, 06:00, 12:00, and 18:00 UTC (https://www.esrl.noaa. gov/psd/data/gridded/data.ncep.reanalysis2.pressure.html). These data have $144 \times 73$ horizontal grids with a grid spacing of $2.5^{\circ}$. From the ground level to $10 \mathrm{hPa}$, there are 17 pressure levels in the vertical direction. The classification of synoptic weather maps is conducted using the gridded data at a geopotential height of $850 \mathrm{hPa}$ during the same time period when the air quality data are recorded. The domain of interest is centered over the YRD region, covering an area of $25-40^{\circ} \mathrm{N}$ in latitude and $110-128^{\circ} \mathrm{E}$ in longitude.

\subsection{HYSPLIT model}

Backward trajectories can be adopted to help understand transport paths and identify the source regions of air masses. The Hybrid Single-Particle Lagrangian Integrated Trajectory (HYSPLIT) Model (Version 4) was developed by the National Oceanic and Atmospheric Administration (NOAA) Air Resources Laboratory (ARL). It is one of the most extensively used atmospheric transport and dispersion models for the study of air parcel trajectories (Draxler and Rolph, 2013; Rolph et al., 2017; Stein et al., 2015), and it has been widely applied in simulations of the complex transport, diffusion, chemical transformation, and deposition processes of atmospheric pollutants (Mcgowan and Clark, 2008; Wang et al., 2011; Huang et al., 2015; Xie et al., 2016b).

In this study, HYSPLIT is used to compute the backward trajectories of air parcels, reveal the possible source regions of air masses, and establish source-receptor relationships for each synoptic weather pattern. For each synoptic weather pattern, the terminus of each trajectory is considered to be located at the observation site in Nanjing $\left(32^{\circ} \mathrm{N}\right.$, $118.8^{\circ} \mathrm{E}$ ). The $72 \mathrm{~h}$ backward trajectories are then calculated and clustered. The ending point is defined as $1500 \mathrm{~m}$ above sea level. The NCEP reanalysis data (http://ready.arl.noaa. gov/archives.php) are used to drive the backward trajectory calculation. The NCEP data contain 6-hourly basic meteorological fields on pressure surfaces with a spatial resolution of $2.5^{\circ}$. In this study, these data are also converted to hemi- 


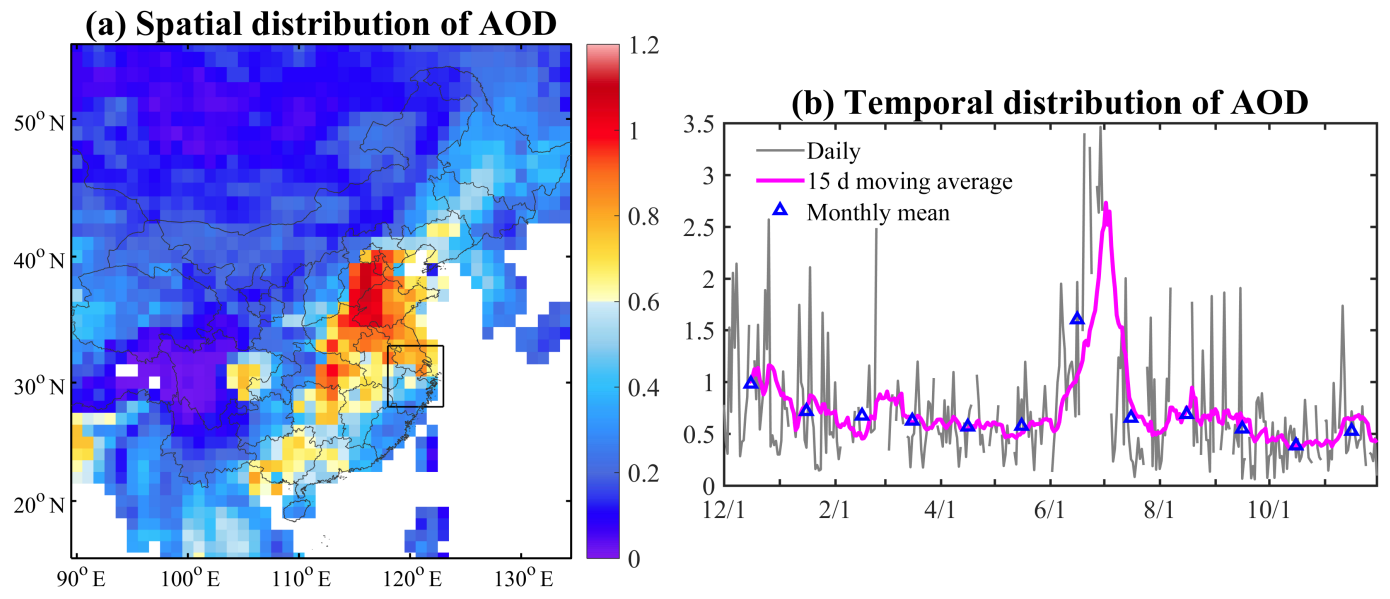

(c) PM2.5

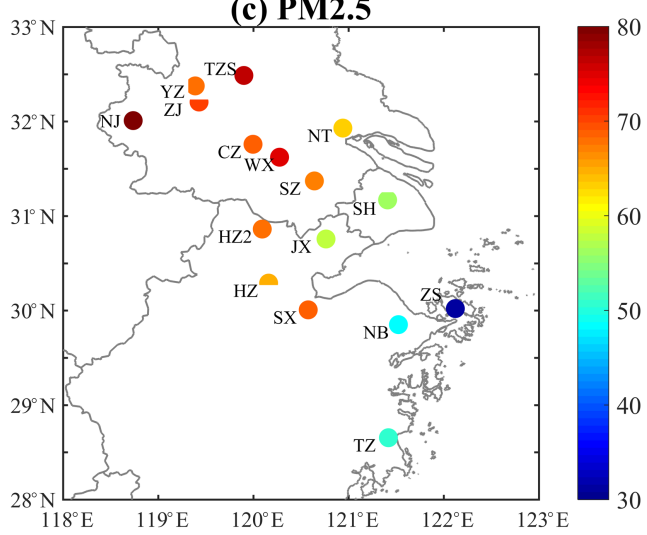

(d) PM10

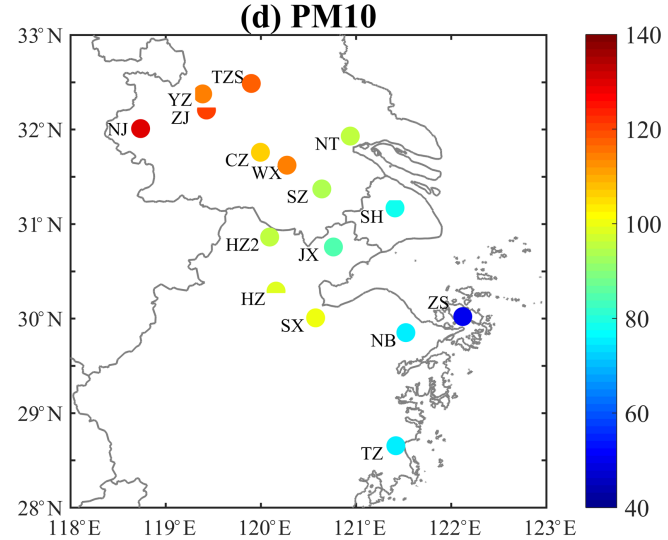

Figure 2. The spatial distribution of annual mean AOD values (at a wavelength of $550 \mathrm{~nm}$ ) over the YRD (a), the temporal variations in regional average AOD values over $28-33^{\circ} \mathrm{N}$ and $118-123^{\circ} \mathrm{E}(\mathbf{b})$, the spatial distribution of annual mean $\mathrm{PM}_{2.5}$ concentrations (c), and the spatial distribution of annual mean $\mathrm{PM}_{10}$ concentrations (d). In (b), the gray line represents the daily value, the blue markers represent the monthly mean values and the magenta line represents the 15-day moving average value. In (c) and (d), the acronyms of each city are marked, including Shanghai - SH, Changzhou - CZ, Nanjing - NJ, Nantong - NT, Suzhou - SZ, Taizhoushi - TZS, Wuxi - WX, Yangzhou - YZ, Zhenjiang - ZJ, Hangzhou - HZ, Huzhou - HZ2, Jiaxing - JX, Ningbo - NB, Shaoxing - SX, Taizhou - TZ, and Zhoushan - ZS.

spheric 144 by 73 polar stereographic grids; these data thus have the same grid configuration as the dataset applied in the synoptic weather classification.

\section{Results and discussion}

\subsection{Characteristics of particle pollution in the YRD}

\subsubsection{Spatial distributions of particle pollution}

Figure 2a displays the annual mean values of AOD observed at a wavelength of $550 \mathrm{~nm}$ throughout most of China. The highest values (i.e., larger than 0.6) generally occur in the BTH, the YRD, the Sichuan Basin (SCB), and some of the central and southern provinces in China (i.e., Hubei, Hunan, and Guangxi provinces). AOD is mainly governed by fine particles in industrialized urban conditions (Kim et al.,
2007); thus, the abovementioned areas should suffer from high columnar aerosol loading. In the YRD, with the development of modern industrialization and urbanization, contrasts in the atmospheric pollution levels among different cities gradually decrease, and severe air pollution episodes tend to exhibit significant regional pollution characteristics.

Figure $2 b$ shows the temporal variations in the regional average AOD values in the YRD (covering 16 cities within the area of $28-33^{\circ} \mathrm{N}$ and $118-123^{\circ} \mathrm{E}$ ). The annual mean value is $0.71 \pm 0.57$. The maximum seasonal value is $0.98 \pm 0.83$ in summer, followed by $0.81 \pm 0.57$ in winter, $0.59 \pm 0.24$ in spring, and $0.48 \pm 0.35$ in autumn. Although the peak particle concentrations are observed in winter (as shown in Figs. 3 and 5), the above results demonstrate that the maximum regional mean AOD values occur in summer, as they reach their highest value of 1.60 in June. This result is similar to that found by Kim et al. (2006), who reported that the value of AOD is not only associated with the pollution levels of fine 

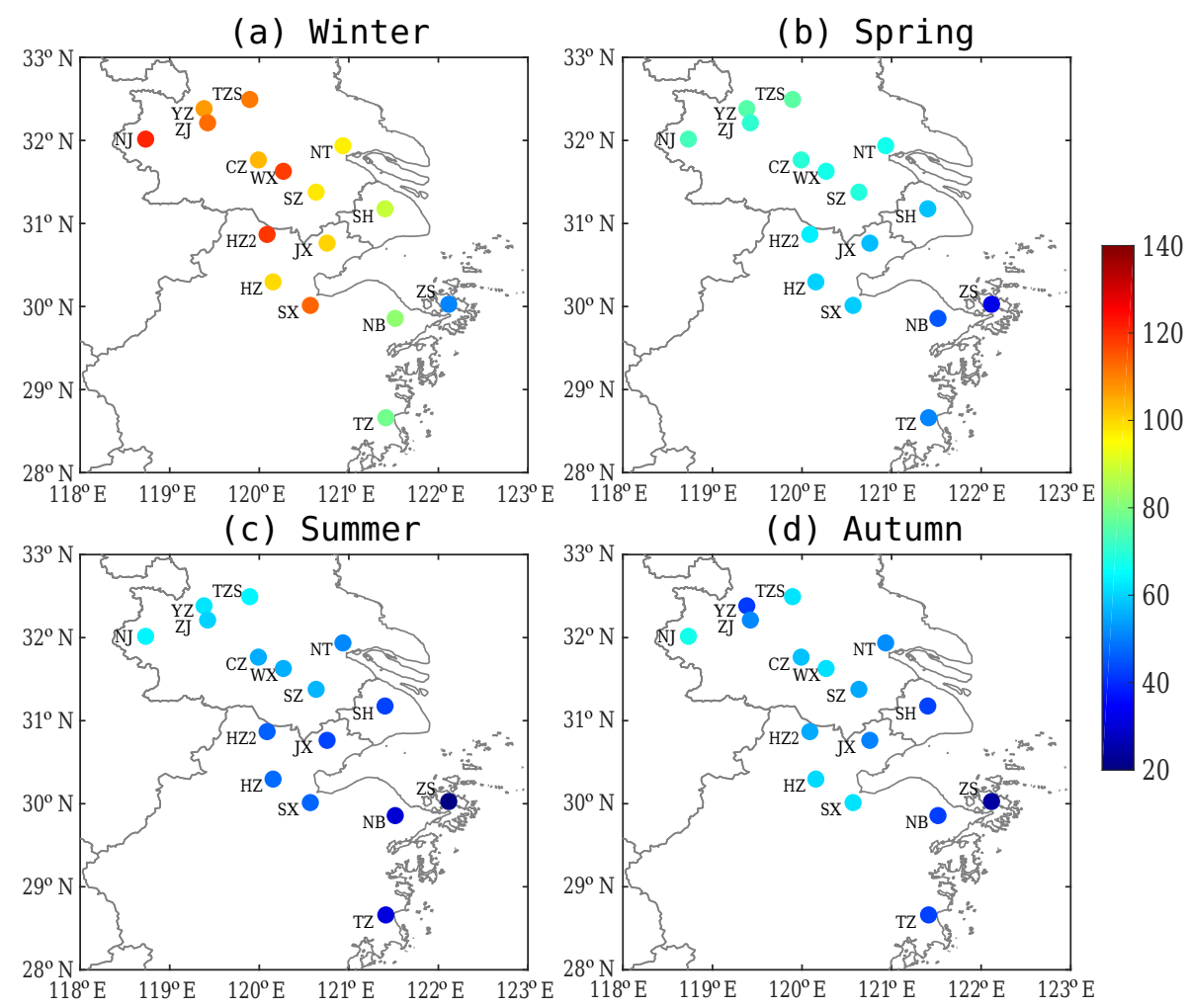

Figure 3. The spatial distribution of seasonal mean $\mathrm{PM}_{2.5}$ over the YRD in (a) winter, (b) spring, (c) summer, and (d) autumn (unit: $\mu g \mathrm{~m}^{-3}$ ). The acronyms for each city are the same as those in Fig. 2.

particles but is also strongly affected by other factors (e.g., solar radiation, water vapor). The fact that the maximum AOD values occur in hot seasons should be ascribed to the combined effects of the increase in fine aerosol production (i.e., due to secondary aerosol formation by gas-to-particle conversion, the hygroscopic growth of hydrophilic aerosols or biomass burning emissions) and humid weather (Kim et al., 2006). Consequently, the AOD data obtained from satellite observations can reveal the spatial distribution of aerosols to some extent, but they cannot exactly reflect pollution levels or replace concentration data.

Figure $2 \mathrm{c}$ and $\mathrm{d}$ show the spatial distributions of the annual mean particle concentrations in 16 typical cities over the YRD from December 2013 to November 2014. Generally, the spatial distributions of $\mathrm{PM}_{2.5}$ (Fig. 2c) and $\mathrm{PM}_{10}$ (Fig. 2d) exhibit overall similar patterns. The annual mean $\mathrm{PM}_{2.5}$ and $\mathrm{PM}_{10}$ values decrease progressively in the northwestsoutheast direction, which means that particle concentrations are comparatively high in the northwest inland areas and low in the southeast coastal areas. The pollution levels in most cities exhibit a positive correlation with their proximity to the sea. The farther a city is from the sea, the higher its particle concentrations are. The maximum particle concentrations occur in Nanjing, with values of $79 \mu \mathrm{g} \mathrm{m}^{-3}$ for $\mathrm{PM}_{2.5}$ and $130 \mu \mathrm{g} \mathrm{m}^{-3}$ for $\mathrm{PM}_{10}$. Previous studies of major climatic features in the YRD have demonstrated that the southeast coastal area is dramatically affected by the land-sea breeze and marine air masses. The clean marine air masses are advantageous to the dilution and diffusion of atmospheric pollutants, thus producing lighter air pollution. However, in the inland region, clustered cities and industrial districts tend to emit more pollutants, thereby resulting in the accumulation of more air pollutants around these cities.

Figure 3 illustrates the spatial distribution of the seasonal mean $\mathrm{PM}_{2.5}$ in 16 cities over the YRD. The pattern observed during each season is similar to the annual mean pattern (Fig. 2c). The $\mathrm{PM}_{2.5}$ pollution levels are much higher in inland cities, and they decrease in the northwest-southeast direction. $\mathrm{PM}_{2.5}$ concentrations exhibit seasonal variations; they are highest in winter, reaching a maximum value of $120 \mu \mathrm{g} \mathrm{m}^{-3}$, and they decrease throughout spring, yielding their lowest values during summer and autumn. The difference between the $\mathrm{PM}_{2.5}$ concentration in summer and that in autumn is relatively small; this difference ranges from a maximum value of lower than $60 \mu \mathrm{g} \mathrm{m}^{-3}$ in Nanjing to a minimum value of close to $20 \mu \mathrm{g} \mathrm{m}^{-3}$ in Zhoushan.

Table 1 quantitatively lists the annual mean concentrations of $\mathrm{PM}_{2.5}$ and $\mathrm{PM}_{10}$ in 16 cities over the YRD. It also demonstrates that the particle pollution levels are relatively higher in inland cities. The concentrations of $\mathrm{PM}_{2.5}$ and $\mathrm{PM}_{10}$ in 8 cities in Jiangsu Province are all higher than $60 \mu \mathrm{g} \mathrm{m}^{-3}$ $\left(\mathrm{PM}_{2.5}\right)$ and $80 \mu \mathrm{g} \mathrm{m}^{-3}\left(\mathrm{PM}_{10}\right)$, respectively. However, these 
concentrations are comparatively lower in the cities located in the coastal area (e.g., Ningbo, Taizhou, and Zhoushan). Only the air quality of Zhoushan meets the national standard, which may be attributed to the fact that it is located on an island where its air is most likely influenced by clean marine air masses.

To reveal the important role of $\mathrm{PM}_{2.5}$ in particle pollution, the ratios of $\mathrm{PM}_{2.5}$ concentration to $\mathrm{PM}_{10}$ concentration $\left(\mathrm{PM}_{2.5} / \mathrm{PM}_{10}\right)$ are calculated over the YRD. As listed in Table 1 , the maximum annual mean value of the $\mathrm{PM}_{2.5}: \mathrm{PM}_{10}$ ratio is 0.72 in Shanghai, followed by Huzhou and Suzhou (0.71), thus implying that the $\mathrm{PM}_{2.5}$ fraction is overwhelmingly dominant relative to the $\mathrm{PM}_{10}$ mass in these cities. The $\mathrm{PM}_{2.5}: \mathrm{PM}_{10}$ ratios in other cities range from 0.60 to 0.69 , with a minimum value of 0.58 in Zhenjiang. These values are comparable to those in other cities, such as Beijing (He et al., 2001), Shanghai (Wang et al., 2013), Taibei (Chen et al., 1999), and Hong Kong (Ho et al., 2003), thus suggesting that the formation of $\mathrm{PM}_{2.5}$ from gases is the most important source of particles in the cities of China. Table 1 also indicates that the $\mathrm{PM}_{2.5}: \mathrm{PM}_{10}$ ratios in all cities exhibit distinct seasonal variation. It is remarkable that the values of $\mathrm{PM}_{2.5}: \mathrm{PM}_{10}$ are much higher in winter than they are in other seasons, reaching a maximum value of 0.85 in Shanghai, followed by a value of 0.82 in Suzhou. The highest concentrations of $\mathrm{PM}_{2.5}$ usually occur in winter (Fig. 3a), and high values of the $\mathrm{PM}_{2.5}: \mathrm{PM}_{10}$ ratio (0.73) also occur during the same season (Table 1), thus indicating that $\mathrm{PM}_{2.5}$ poses a greater threat to human health in cold seasons, which may be related to heating activities. In summer, the values of $\mathrm{PM}_{2.5}: \mathrm{PM}_{10}$ in the 16 cities are medium, with a mean value of 0.67 . The lowest ratios usually occur in spring and autumn, when the mean ratios of all cities are 0.61 (spring) and 0.63 (autumn). The minimum value occurs in the autumn in Yangzhou, with a value of 0.51 , followed by a value of 0.52 in the spring in Nanjing and the autumn in Zhenjiang. The above discussion of the spatial and temporal variations in $\mathrm{PM}_{2.5}: \mathrm{PM}_{10}$ ratios also implies that particles originate from various kinds of sources and are variedly emitted.

\subsubsection{Temporal variations in particle pollution}

Figure 4 shows the annual mean diurnal variations in $\mathrm{PM}_{2.5}$ (Fig. 4a) and $\mathrm{PM}_{10}$ (Fig. 4b) in 16 cities over the YRD. Obviously, the diurnal cycles of particle concentrations in most cities follow a similar pattern. The $\mathrm{PM}_{2.5}$ concentrations maintain comparably high values from 00:00 to 08:00. Then, coinciding with more vehicle emissions during rush hours, these concentrations increase rapidly from 08:00 to 12:00. After reaching their peak, the $\mathrm{PM}_{2.5}$ concentrations decrease and remain at low values until sunset. During nighttime, the pollutants accumulate until midnight, which can be attributed to the more stable atmospheric stratification in the boundary layer. In comparison, there are two peaks in the diurnal cycles of the $\mathrm{PM}_{10}$ concentrations in several cities. The (a) PM2.5

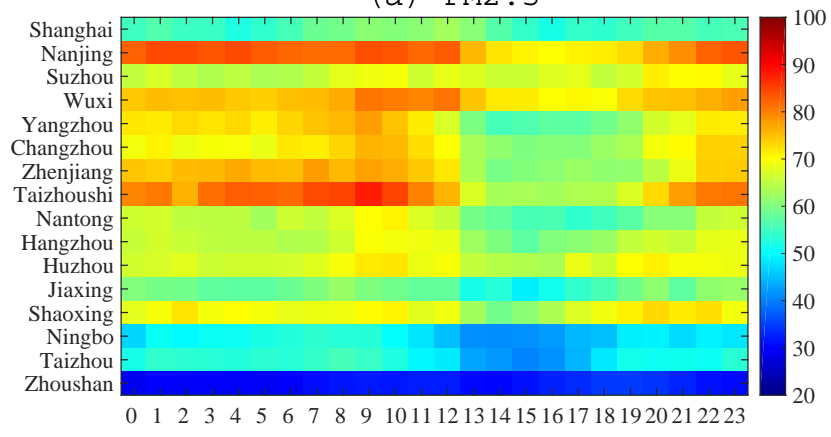

(b) PM10

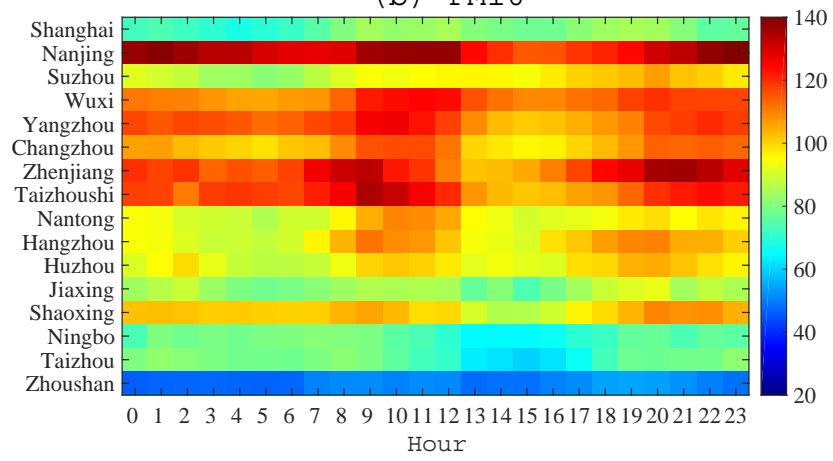

Figure 4. Diurnal variations in $\mathrm{PM}_{2.5}$ (a) and $\mathrm{PM}_{10}$ (b) concentrations in 16 cities of the YRD (unit: $\mu \mathrm{g} \mathrm{m}^{-3}$ ).

broad morning peak of $\mathrm{PM}_{10}$ concentrations is more evident from 08:00 to 12:00, and the evening peak occurs at approximately 20:00. In addition, the diurnal change in particle concentrations in the southeast coastal area, such as Zhoushan, is much smaller. As discussed in Sect. 3.1.1, this difference might be related to its special geographic location, which exhibits fewer emissions of precursors and lower pollution levels.

Figure 5 shows the monthly mean concentrations of $\mathrm{PM}_{2.5}$ and $\mathrm{PM}_{10}$ in 16 cities of the YRD. As illustrated in this figure, there are three peaks in the seasonal variations in particles. These three peaks occur in December, March, and May/June. This monthly variation pattern is more obvious for $\mathrm{PM}_{10}$. The causes resulting in the wintertime peak of particle concentrations can be explained by two factors. One is the enhanced emissions of pollutants from residential heating. The other is the stable and poor meteorological conditions that limit the diffusion of atmospheric pollutants. The drivers of the peak appearing in March may be associated with dust storm events in spring (Zhuang et al., 2001; Fu et al., 2010, 2014). As discussed in Sect. 3.1.1, the values of the $\mathrm{PM}_{2.5}: \mathrm{PM}_{10}$ ratio in 16 cities are lowest in spring, with a mean ratio of 0.61 . High $\mathrm{PM}_{10}$ concentrations during this period further demonstrate that dust storms can bring more coarse dust particles to the YRD. The peak in May/June is probably caused by the field burning of crop residue in rural areas of China, which is regarded to be an important source 
Table 1. Annual mean concentrations of $\mathrm{PM}_{2.5}$ and $\mathrm{PM}_{10}$ and the annual and seasonal mean values of $\mathrm{PM}_{2.5}: \mathrm{PM}_{10}$ ratios in 16 cities of the YRD.

\begin{tabular}{|c|c|c|c|c|c|c|c|c|}
\hline \multicolumn{2}{|c|}{ Cities } & \multirow[t]{2}{*}{$\mathrm{PM}_{2.5}\left(\mu \mathrm{g} \mathrm{m}^{-3}\right)$} & \multirow[t]{2}{*}{$\mathrm{PM}_{10}\left(\mu \mathrm{g} \mathrm{m}^{-3}\right)$} & \multicolumn{5}{|c|}{$\mathrm{PM}_{2.5}: \mathrm{PM}_{10}$} \\
\hline & & & & Annual & Winter & Spring & Summer & Autumn \\
\hline \multicolumn{2}{|c|}{ Shanghai } & 56 & 78 & 0.72 & 0.85 & 0.68 & 0.72 & 0.66 \\
\hline \multirow{8}{*}{ Jiangsu Province } & Nanjing & 79 & 130 & 0.61 & 0.64 & 0.52 & 0.70 & 0.60 \\
\hline & Changzhou & 69 & 106 & 0.65 & 0.73 & 0.60 & 0.67 & 0.62 \\
\hline & Nantong & 63 & 95 & 0.66 & 0.72 & 0.62 & 0.71 & 0.64 \\
\hline & Suzhou & 67 & 94 & 0.71 & 0.82 & 0.68 & 0.71 & 0.67 \\
\hline & Taizhoushi & 76 & 117 & 0.65 & 0.66 & 0.58 & 0.72 & 0.66 \\
\hline & Wuxi & 75 & 114 & 0.66 & 0.73 & 0.59 & 0.67 & 0.62 \\
\hline & Yangzhou & 68 & 114 & 0.60 & 0.69 & 0.58 & 0.59 & 0.51 \\
\hline & Zhenjiang & 70 & 121 & 0.58 & 0.71 & 0.54 & 0.58 & 0.52 \\
\hline \multirow[t]{7}{*}{ Zhejiang Province } & Hangzhou & 65 & 99 & 0.66 & 0.74 & 0.59 & 0.63 & 0.66 \\
\hline & Huzhou & 68 & 96 & 0.71 & 0.78 & 0.66 & 0.68 & 0.69 \\
\hline & Jiaxing & 58 & 84 & 0.69 & 0.75 & 0.65 & 0.68 & 0.69 \\
\hline & Ningbo & 48 & 75 & 0.64 & 0.69 & 0.62 & 0.63 & 0.62 \\
\hline & Shaoxing & 68 & 100 & 0.68 & 0.72 & 0.62 & 0.71 & 0.68 \\
\hline & Taizhou & 50 & 75 & 0.67 & 0.69 & 0.66 & 0.66 & 0.65 \\
\hline & Zhoushan & 31 & 50 & 0.63 & 0.66 & 0.62 & 0.66 & 0.55 \\
\hline
\end{tabular}

of biomass burning (Yan et al., 2006; Yang et al., 2008; Zhu et al., 2012).

\subsubsection{Regional severe particle pollution in the YRD}

According to the National Ambient Air Quality Standard (NAAQS) of China, urban air quality must meet the second standard, with daily mean concentrations of $\mathrm{PM}_{2.5}$ and $\mathrm{PM}_{10}$ that are lower than 75 and $150 \mu \mathrm{g} \mathrm{m}^{-3}$, respectively. In this study, when the daily mean $\mathrm{PM}_{2.5}\left(\mathrm{PM}_{10}\right)$ concentrations exceed the national air quality standard in most (i.e., 8 or more) of the 16 cities, we define this as large-scale regional $\mathrm{PM}_{2.5}\left(\mathrm{PM}_{10}\right)$ pollution. Consequently, from December 2013 to November 2014, there were 98 (46) days when large-scale regional $\mathrm{PM}_{2.5}\left(\mathrm{PM}_{10}\right)$ pollution episodes were identified. That is, the YRD suffered from regional $\mathrm{PM}_{2.5}$ $\left(\mathrm{PM}_{10}\right)$ pollution during nearly $28.0 \%(13.1 \%)$ of the days of the year.

Table 2 shows the typical regional severe particle pollution episodes (that lasted no less than 3 days) in the YRD from December 2013 to November 2014. As illustrated in this table, dozens of continuous large-scale particle pollution episodes occurred. For example, $\mathrm{PM}_{2.5}$ concentrations exceeded the national standard in all 16 cities from December 1 to 5, 2013, and there were more than 14 cities facing heavy $\mathrm{PM}_{10}$ pollution at the same time. From 26 to 30 May 2014, serious $\mathrm{PM}_{2.5}$ and $\mathrm{PM}_{10}$ pollution episodes were observed in more than 10 cities. It appears that high- $\mathrm{PM}_{2.5}$ pollution episodes are remarkably associated with high$\mathrm{PM}_{10}$ pollution episodes. Moreover, regional $\mathrm{PM}_{2.5}$ pollution episodes occurred much more frequently than $\mathrm{PM}_{10}$ pollu- (a) PM2.5

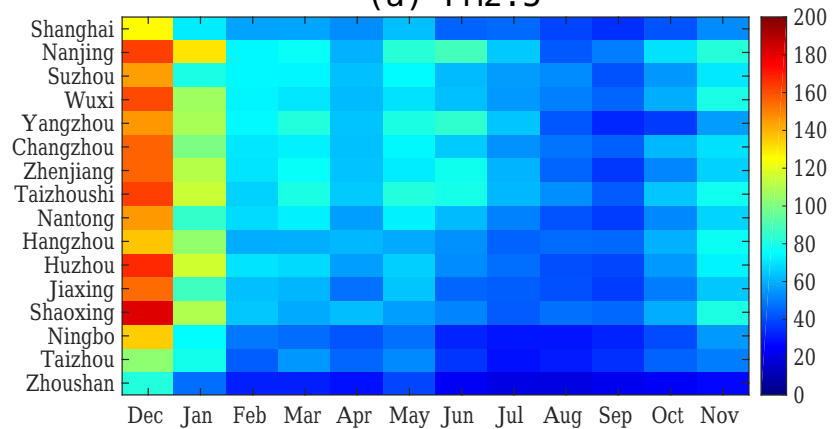

(b) PM10

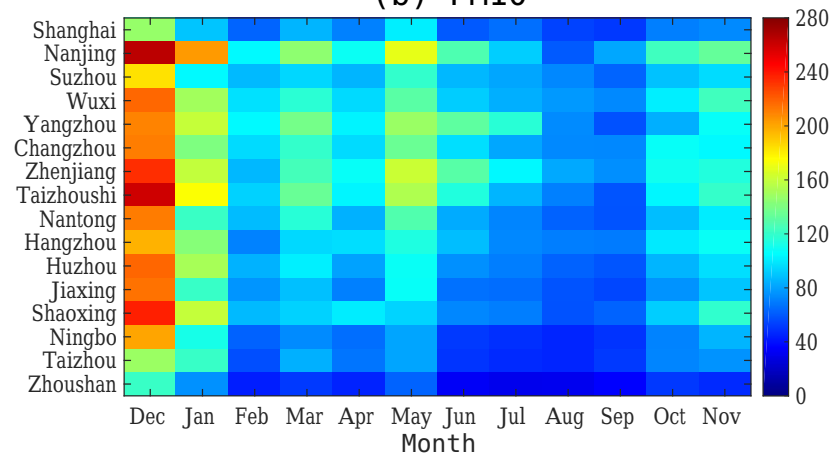

Figure 5. Monthly variations in $\mathrm{PM}_{2.5}$ (a) and $\mathrm{PM}_{10}$ (b) concentrations in 16 cities of the YRD (unit: $\mu \mathrm{g} \mathrm{m}^{-3}$ ).

tion episodes. This may be due to the fact that fine particles dominate the composition of particles in the YRD (as discussed in Sect. 3.1.2). 
Table 2. The typical regional severe particle pollution episodes (lasting for no less than 3 days) in the YRD from December 2013 to November 2014.

\begin{tabular}{ll}
\hline Episodes of $\mathrm{PM}_{2.5}$ pollution & Episodes of $\mathrm{PM}_{10}$ pollution \\
\hline 1-6 Dec & 1-6 Dec \\
11-15 Dec & 12-15 Dec \\
24-26 Dec & 24-26 Dec \\
28 Dec-6 Jan & 29 Dec-5 Jan \\
15-20 Jan & 17-20 Dec \\
30 Jan-2 Feb & 26-30 May \\
20-24 Feb & \\
16-18 Mar & \\
8-10 Apr & \\
20-22 May & \\
26-30 May & \\
5-7 Jun & \\
28 Jun-1 Jul & \\
10-12 Nov & \\
\hline
\end{tabular}

\subsection{Synoptic weather classification}

In this study, to examine the relationship between regional severe particle pollution in the YRD and weather situations, synoptic weather classification is carried out from December 2013 to November 2014. Using the method described in Sect. 2.2, we conduct the classification of the synoptic weather pattern by using the dataset of geopotential height at $850 \mathrm{hPa}$ collected from the NCEP reanalysis data. As shown in Table 3, five weather patterns are finally identified. Unknown patterns are defined as "the unclassified pattern". The weather situation on $95.6 \%$ of the days during the study period is classified as one of the five typical synoptic weather patterns.

Table 3 lists the typical date, number of days, and seasonal occurrence frequencies of each synoptic weather pattern. As demonstrated in this table, Pattern 1 is the dominant weather pattern in the YRD, which accounts for $47.6 \%$ of all of the days of the year (from December 2013 to November 2014). The occurrence frequencies of Patterns 2 and 3 are 20.0 and $18.1 \%$, respectively. Patterns 4 and 5 are identified on the fewest number of days, with occurrence frequencies of 4.1 and $5.8 \%$, respectively.

Table 3 also shows the seasonal occurrence frequencies of each pattern from December 2013 to November 2014. Obviously, they are distinctly different. Pattern 1 tends to occur in winter, with a frequency of $30.5 \%$, followed by spring $(25.9 \%)$, summer $(21.8 \%)$, and autumn $(21.8 \%)$. Pattern 2 is the most popular weather pattern in summer, with an occurrence frequency of $37.0 \%$, followed by spring (30.1\%), autumn $(21.9 \%)$, and winter $(11.0 \%)$. For Pattern 3, the seasonal frequencies occur in the order of winter $(36.4 \%)$, spring $(27.3 \%)$, autumn $(19.7 \%)$, and summer $(16.7 \%)$. Both Pattern 4 and Pattern 5 are most likely to occur in au- tumn, with occurrence frequencies of 53.3 and $42.9 \%$, respectively. The occurrence frequencies of Pattern 4 and Pattern 5 during other seasons account for nearly $50 \%$.

\subsection{Effects of synoptic weather patterns on particle pollution}

\subsubsection{Relationship between synoptic weather pattern and particle pollution}

To determine the relationship between synoptic weather patterns and particle pollution, the occurrence frequencies of the five typical synoptic patterns during the regional severe particle pollution episodes are calculated. As shown in Table 4, during the days with regional $\mathrm{PM}_{2.5}\left(\mathrm{PM}_{10}\right)$ pollution episodes, Pattern 1 is the dominant synoptic weather pattern, with an occurrence frequency of $70.4 \%$ (78.3\%). Pattern 2 and Pattern 3 both occur on $14.3 \%$ of the days with $\mathrm{PM}_{2.5}$ pollution episodes. During $\mathrm{PM}_{10}$ pollution episodes, Pattern $2(6.5 \%)$ appears less frequently than Pattern $3(15.2 \%)$. The occurrence frequencies of Pattern 4 and Pattern 5 are less than $1 \%$ and can thus almost be ignored.

According to Tables 3 and 4 , the occurrence frequency of Pattern 1 during regional particle pollution episodes is obviously higher than its occurrence during the entire year. In contrast, the occurrences of Pattern 2 and Pattern 3 during these episodes are less frequent than those throughout the year. Moreover, Pattern 4 and Pattern 5 appear far less frequently during regional particle pollution episodes than they do throughout the year. In summary, these data suggest that the weather situation of Pattern 1 is more beneficial for the formation of large-scale regional particle pollution in the YRD.

Figure 6 shows the box-and-whisker plot of the mean concentrations of air pollutants $\left(\mathrm{PM}_{10}, \mathrm{PM}_{2.5}, \mathrm{O}_{3}, \mathrm{NO}_{2}, \mathrm{SO}_{2}\right.$, and $\mathrm{CO}$ ) and the meteorological parameters (WS, $T, P$, and $\mathrm{RH})$ of 16 cities under the five synoptic weather patterns, as well as the corresponding spatial distribution of AOD over eastern China. These statistical results are also listed in Table 5 .

As shown in Fig. 6a-f and Table 5, the highest average concentrations of the main air pollutants (except for $\mathrm{O}_{3}$ ) in the 16 cities in the YRD are associated with Pattern 1. Since aerosols can reflect and absorb solar radiation and thereby cause the photochemical production of $\mathrm{O}_{3}$ to decrease (Kaufman et al., 2002), the $\mathrm{O}_{3}$ concentration is lowest for Pattern 1 (Fig. 6c). As mentioned above, Pattern 1 is most likely to occur during winter $(30.5 \%)$ and spring $(25.9 \%)$. Therefore, the weather situation of this pattern features the weakest surface wind, lowest humidity, second-highest surface pressure, and low temperature. All of these weather characteristics are conducive to the accumulation of particles and their precursors (i.e., $\mathrm{SO}_{2}, \mathrm{NO}_{2}$, and $\mathrm{CO}$ ). For Pattern 3 , the concentrations of $\mathrm{PM}_{10}, \mathrm{PM}_{2.5} \mathrm{NO}_{2}$, and $\mathrm{SO}_{2}$ are the second-highest compared to those of the other patterns. This pattern features 
Table 3. The typical date, number of days, and seasonal occurrence frequencies of each synoptic weather pattern.

\begin{tabular}{lllrrrr}
\hline \multirow{2}{*}{ Type } & Typical date & Number of days & \multicolumn{3}{c}{ Occurrence frequency (\%) } \\
\cline { 4 - 6 } & & & Spring & Summer & Autumn & Winter \\
\hline Pattern 1 & $2014-05-12$ & $174(47.7 \%)$ & 25.9 & 21.8 & 21.8 & 30.5 \\
Pattern 2 & $2014-05-09$ & $73(20.0 \%)$ & 30.1 & 37.0 & 21.9 & 11.0 \\
Pattern 3 & $2014-02-18$ & $66(18.1 \%)$ & 27.3 & 16.7 & 19.7 & 36.4 \\
Pattern 4 & $2014-10-07$ & $15(4.1 \%)$ & 13.3 & 26.7 & 53.3 & 6.7 \\
Pattern 5 & $2014-09-14$ & $21(5.8 \%)$ & 19.0 & 23.8 & 42.9 & 14.3 \\
Unclassified pattern & - & $16(4.4 \%)$ & - & - & - & - \\
\hline
\end{tabular}

Table 4. The occurrence frequencies of synoptic weather patterns during regional severe $\mathrm{PM}_{2.5}$ and $\mathrm{PM}_{10}$ pollution episodes.

\begin{tabular}{lrr|rr}
\hline Type & \multicolumn{2}{c|}{ PM $_{2.5}$} & \multicolumn{2}{c}{ PM $_{10}$} \\
\cline { 2 - 5 } & Number of days & Frequency (\%) & Number of days & Frequency (\%) \\
\hline Pattern 1 & 69 & 70.4 & 36 & 78.3 \\
Pattern 2 & 14 & 14.3 & 3 & 6.5 \\
Pattern 3 & 14 & 14.3 & 7 & 15.2 \\
Pattern 4 & 0 & 0 & 0 & 0 \\
Pattern 5 & 1 & 1.0 & 0 & 0 \\
\hline
\end{tabular}

the highest surface pressure and much stronger surface wind. The temperature is the lowest, as Pattern 3 also tends to occur during winter $(36.4 \%)$ and spring $(27.3 \%)$. Under the weather situation of Pattern 1 and Pattern 3, the YRD is both under the control of high pressure and likely to suffer serious particle pollution. The strength of the surface wind for different weather patterns plays a key role in the occurrence frequency of regional severe particle pollution episodes. Pattern 1 , which has the weakest surface wind, is regarded as "the most polluted pattern". The pollution levels of the main pollutants in Pattern 2 are in the middle and slightly lower than those of Pattern 3. Due to its high occurrence frequency in summer $(37.0 \%)$ and spring $(30.1 \%)$, the weather condition of Pattern 2 is characterized by its relatively high temperature, low pressure, and the lowest RH. In contrast, Pattern 4 and Pattern 5 are "the clean patterns", in which the concentrations of all of their pollutants are distinctly lower than those of the other three patterns. Their meteorological conditions of relatively high humidity, high temperature, strong wind (especially for Pattern 5), and much lower surface pressure are also favorable for the mitigation of pollutants.

Figure 6k to o display the spatial distribution of AOD over eastern China under different synoptic weather patterns. The regional mean values of AOD in the YRD $\left(28-33^{\circ} \mathrm{N}, 118-\right.$ $123^{\circ} \mathrm{E}$ ) are 0.74 for Pattern 1, 0.64 for Pattern 2, 0.81 for Pattern 3, 0.47 for Pattern 4, and 0.49 for Pattern 5. Additionally, AOD is higher over the YRD for Pattern 3, Pattern 1, and Pattern 2. For these three patterns, high AOD values usually occur in the BTH, the YRD, and the SCB, as well as the provinces of Shanxi, Shandong, Hubei, Hunan, Anhui, and Guangxi. The highest AOD values are mainly found in northeastern China. For Pattern 4 and Pattern 5, high AOD values are mostly concentrated in the BTH and Shandong Province, while relatively low AOD values are found in the YRD. Since AOD is closely related to the concentrations of fine particles, it can be concluded that the YRD is most heavily polluted under the weather situations of Pattern 1 and Pattern 3 .

\subsubsection{The impact mechanism of synoptic weather patterns on severe particle pollution}

Figures 7-11 present the meteorological fields and backward trajectories under the weather situations of the Pattern 1 (northwesterly inland wind), Pattern 2 (southwesterly), Pattern 3 (northerly inland wind), Pattern 4 (cyclonerelated) and Pattern 5 (oceanic-circulation-related). The first two graphs of Figs. 7-11 illustrate the 850 and $500 \mathrm{hPa}$ geopotential height field and wind field, respectively. The third graphs display the sea level pressure field and $1000 \mathrm{hPa}$ wind field. The highlighted boxes denote the study area (i.e., the YRD). The fourth graphs demonstrate the heightlatitude cross-sections of vertical velocity over the latitudes of $25-40^{\circ} \mathrm{N}$, which are averaged over the longitudes of $110-128^{\circ} \mathrm{E}$. The bold black lines show the latitude range of 16 cities $\left(28.6-32.5^{\circ} \mathrm{N}\right)$ over the YRD. The positive wind speeds $\left(10^{2} \mathrm{~Pa} \mathrm{~s}^{-1}\right)$ represent vertical downward atmospheric motions, while the negative wind speeds represent upward motions. In addition, it is well known that atmospheric pollutant transport trajectories are deeply affected by synoptic systems. As shown in the fifth graphs in Figs. 711 , to reveal how the typical synoptic weather patterns influ- 
Table 5. The average values of air pollutant concentrations $\left(\mu \mathrm{g} \mathrm{m}^{-3}\right.$ for $\mathrm{PM}_{10}, \mathrm{PM}_{2.5}, \mathrm{O}_{3}, \mathrm{NO}_{2}$ and $\mathrm{SO}_{2} ; \mathrm{mg} \mathrm{m}^{-3}$ for $\left.\mathrm{CO}\right)$ and meteorological factors for the 16 typical YRD cities under different synoptic weather patterns.

\begin{tabular}{|c|c|c|c|c|c|c|c|c|c|c|}
\hline Type & $\mathrm{PM}_{10}$ & $\mathrm{PM}_{2.5}$ & $\mathrm{O}_{3}$ & $\mathrm{NO}_{2}$ & $\mathrm{CO}$ & $\mathrm{SO}_{2}$ & $\mathrm{WS}\left(\mathrm{m} \mathrm{s}^{-1}\right)$ & $T\left({ }^{\circ} \mathrm{C}\right)$ & $P(\mathrm{hPa})$ & $\mathrm{RH}(\%)$ \\
\hline Pattern 1 & $116.5 \pm 66.9$ & $75.9 \pm 49.9$ & $57.7 \pm 27.3$ & $46.9 \pm 19.2$ & $1.08 \pm 0.41$ & $29.3 \pm 17.1$ & $1.84 \pm 0.67$ & $15.8 \pm 7.8$ & $1015.0 \pm 8.5$ & $72.3 \pm 14.4$ \\
\hline Pattern 2 & $81.5 \pm 38.4$ & $52.3 \pm 27.4$ & $65.5 \pm 23.6$ & $36.1 \pm 13.4$ & $0.86 \pm 0.24$ & $20.6 \pm 9.9$ & $2.38 \pm 0.88$ & $20.3 \pm 6.3$ & $1011.2 \pm 6.7$ & $79.8 \pm 10.2$ \\
\hline Pattern 3 & $86.9 \pm 49.5$ & $59.1 \pm 37.3$ & $58.5 \pm 25.5$ & $35.1 \pm 15.5$ & $0.96 \pm 0.35$ & $23.3 \pm 15.9$ & $2.59 \pm 0.87$ & $13.4 \pm 8.2$ & $1016.1 \pm 9.6$ & $76.0 \pm 11.6$ \\
\hline Pattern 4 & $66.1 \pm 18.8$ & $40.7 \pm 15.9$ & $76.8 \pm 19.6$ & $29.4 \pm 9.8$ & $0.72 \pm 0.17$ & $19.4 \pm 6.4$ & $2.29 \pm 0.64$ & $21.7 \pm 4.9$ & $1011.8 \pm 7.0$ & $75.4 \pm 5.8$ \\
\hline Pattern 5 & $58.7 \pm 31.3$ & $37.4 \pm 22.5$ & $61.1 \pm 20.6$ & $29.1 \pm 11.1$ & $0.77 \pm 0.22$ & $17.8 \pm 8.4$ & $2.63 \pm 0.93$ & $19.4 \pm 8.0$ & $1011.1 \pm 6.9$ & $81.0 \pm 9.8$ \\
\hline
\end{tabular}
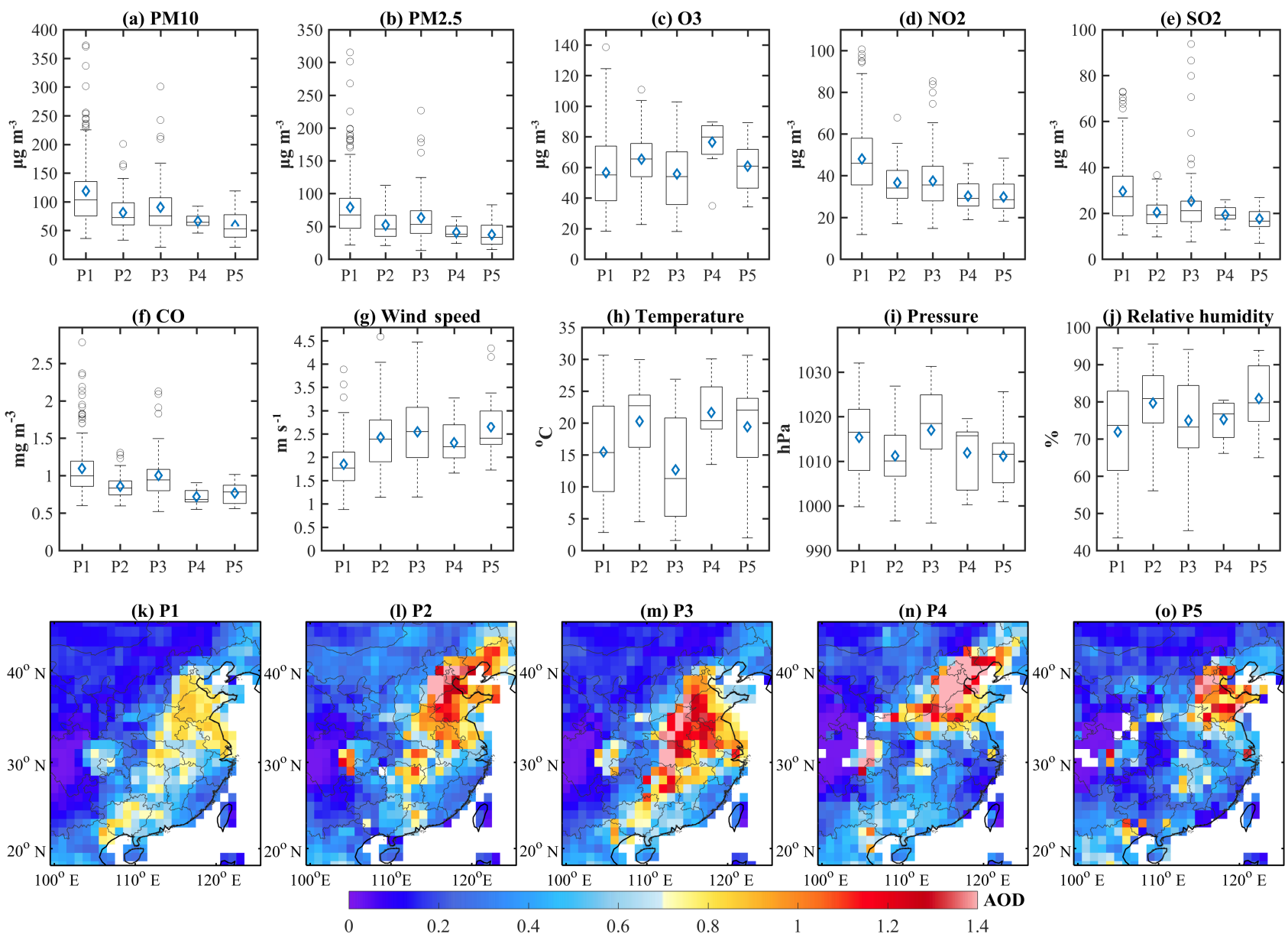

Figure 6. (a-j) Box-and-whisker plots for the mean values of air pollutant concentrations and meteorological parameters of 16 typical YRD cities. The edges of each box in $(\mathbf{a}-\mathbf{j})$ are the 25 th and 75 th percentiles, the band inside the box is the median, the diamond is the average, and the whiskers extend to the most extreme data values. (k-p) Spatial distributions of AOD for the five synoptic weather patterns. P1, P2, P3, P4, and P5 represent Pattern 1, Pattern 2, Pattern 3, Pattern 4, and Pattern 5, respectively.

ence the distribution of particles in the YRD, the $72 \mathrm{~h}$ backward trajectories are calculated and then clustered. Given that Nanjing is the most polluted city in the YRD, as described in Sect. 3.1, the observational site in Nanjing $\left(32^{\circ} \mathrm{N}, 118.8^{\circ} \mathrm{E}\right)$ is chosen for the terminus of the trajectory of each synoptic weather pattern.

As illustrated in Fig. 7a, Pattern 1 usually occurs when the YRD is located at the rear of the East Asian major trough and is under the control of a high-pressure ridge at
$850 \mathrm{hPa}$. The center of the high-pressure system is located in the northwestern Pacific Ocean. Meanwhile, northeastern China is strongly affected by a low-pressure system, namely, the Aleutian Low. The strong horizontal northwest wind at the rear of the East Asian major trough can transport pollutants from the BTH (with high AOD; as shown in Fig. 6k) to the YRD. At the same time, the west and southwest wind at the rear of the high-pressure ridge can also transport pollutants from central and southwestern China (such as the SCB 

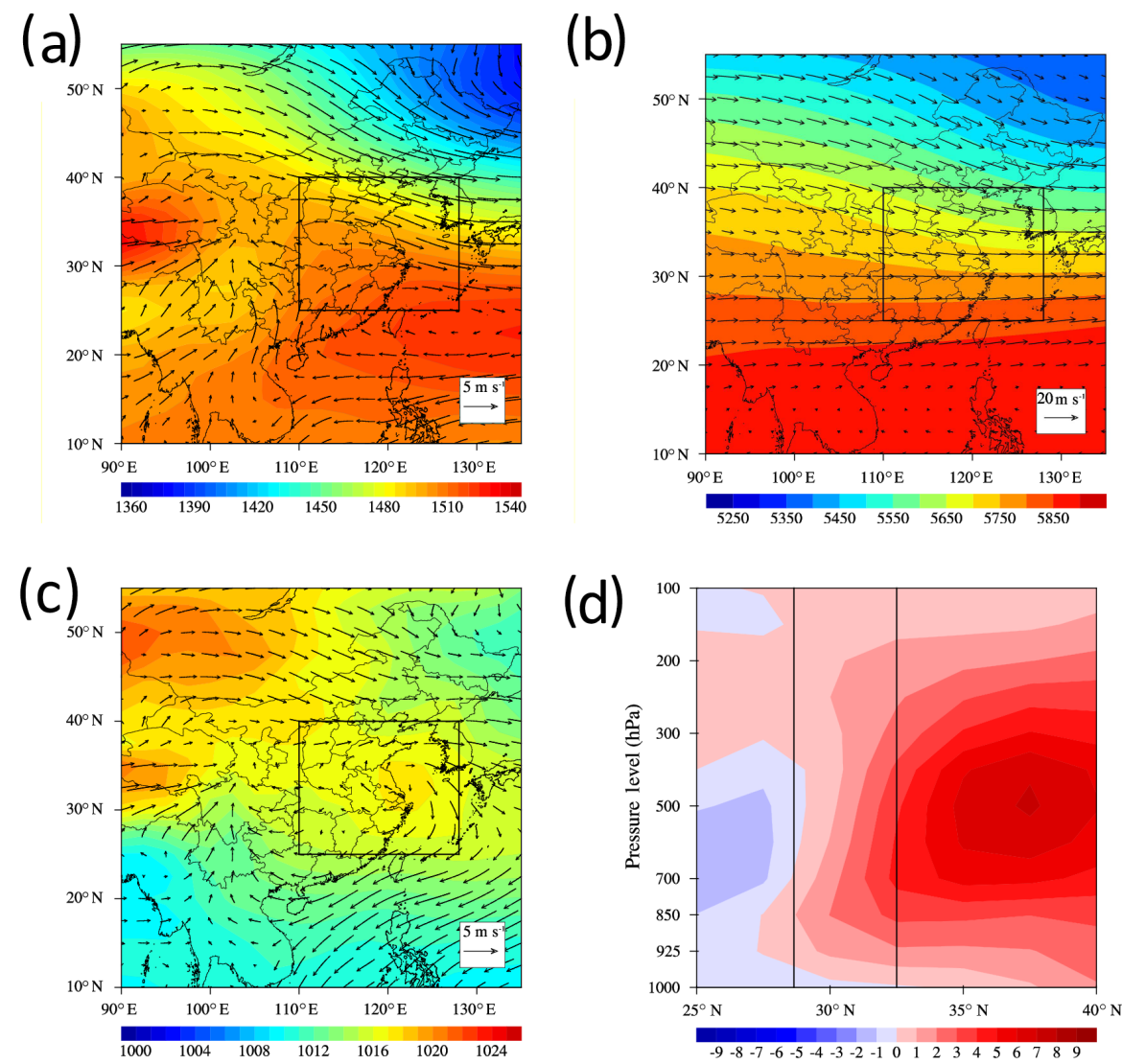

(d)
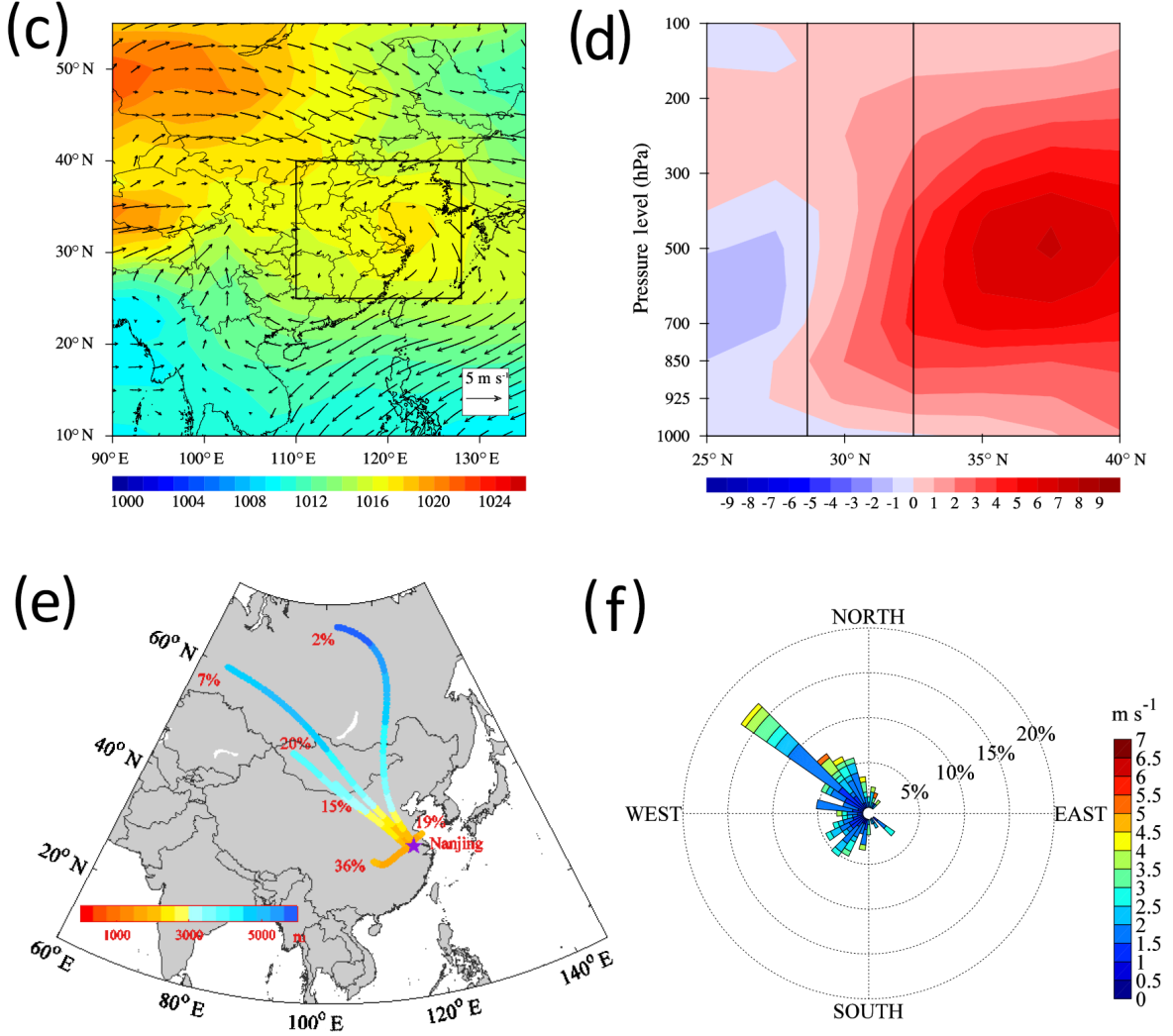

Figure 7. Weather condition in Pattern 1. (a) $850 \mathrm{hPa}$ geopotential height field and wind field, (b) $500 \mathrm{hPa}$ geopotential height field and wind field, (c) sea level pressure field and $1000 \mathrm{hPa}$ wind field, (d) height-latitude cross-sections of vertical velocity (unit: $10^{-2} \mathrm{~Pa} \mathrm{~s}{ }^{-1}$ ) averaged over longitude of $110-128^{\circ} \mathrm{E}$, (e) $72 \mathrm{~h}$ backward trajectory ending at a height of $1500 \mathrm{~m}$, and (f) observation wind rose plots in Nanjing. In (a-c), the highlighted boxes denote the study area (i.e., the YRD). In (d), the black rectangular region represents the 16 cities in the YRD $\left(28.6-32.5^{\circ} \mathrm{N}\right)$. In $(\mathbf{e})$, the purple marker indicates the location of Nanjing $\left(32^{\circ} \mathrm{N}, 118.8^{\circ} \mathrm{E}\right)$. These data represent averages for all days corresponding to Pattern 1.

and Guangxi Province) to the YRD. The confluence of air flows may cause an accumulation of pollutants in the YRD. Accordingly, the atmospheric circulation at $500 \mathrm{hPa}$ features a shallow through with a west-northwest flow (Fig. 7b). The sea level pressure pattern is nearly dominated by a uniform pressure field, which exhibits relatively weak anti-cyclonic circulation over the YRD (Fig. 7c). The above discussion can be further explained by the $72 \mathrm{~h}$ backward trajectories displayed in Fig. 7e. When the YRD is under the control of Pattern 1, the air masses are mainly from northern China (44\%), followed by the central $(36 \%)$ and northeastern regions of the YRD (19\%). This suggests that particle pollution is remarkably affected by the polluted air masses from the BTH and the central city clusters. Surface meteorolog- 

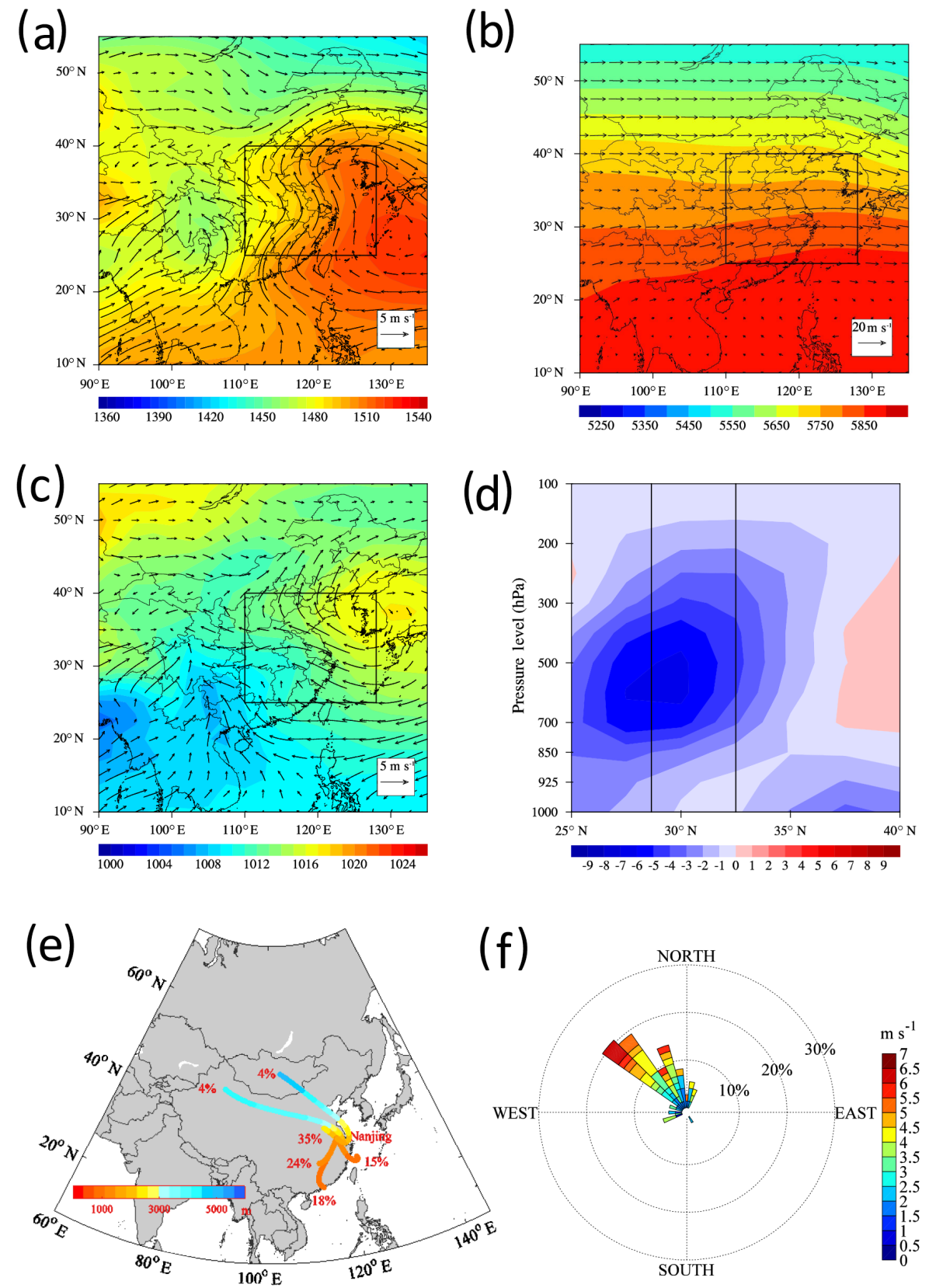

Figure 8. As in Fig. 7, but for Pattern 2.

ical observation records also indicate that west-northwestsouthwest surface winds are dominant in Nanjing (Fig. 7f) and that high $\mathrm{PM}_{2.5}$ is closely associated with the transport of polluted air masses in these wind directions. In the vertical section (Fig. 7d), the relatively weak upward air flows are dominant to the south of $30^{\circ} \mathrm{N}$, while clear downward air flows are prevalent to the north of $30^{\circ} \mathrm{N}$. The largest descending velocity $\left(\sim 8 \times 10^{-2} \mathrm{~Pa} \mathrm{~s}^{-1}\right)$ appears at an altitude of $500 \mathrm{hPa}$ and a latitude of $37.5^{\circ} \mathrm{N}$. Downward motion is dominant above the YRD, which is in accordance with the $850 \mathrm{hPa}$ circulation pattern represented by a high-pressure ridge. Thus, the weather conditions are relatively stable near the surface, which is beneficial to the local accumulation of pollutants. Overall, Pattern 1 represents a stable synoptic weather pattern that is extremely conducive to the build-up of atmospheric pollutants over the YRD. This result is consistent with the findings of Zheng et al. (2015b).

In Pattern 2, a low-pressure center (the southeast vortex) is centered in the SCB, the East China Sea is influenced by a high-pressure system, and a depression inverted trough extends and covers the YRD region at a latitude at $850 \mathrm{hPa}$ (Fig. 8a). Consequently, in the YRD, the strong southwest air 

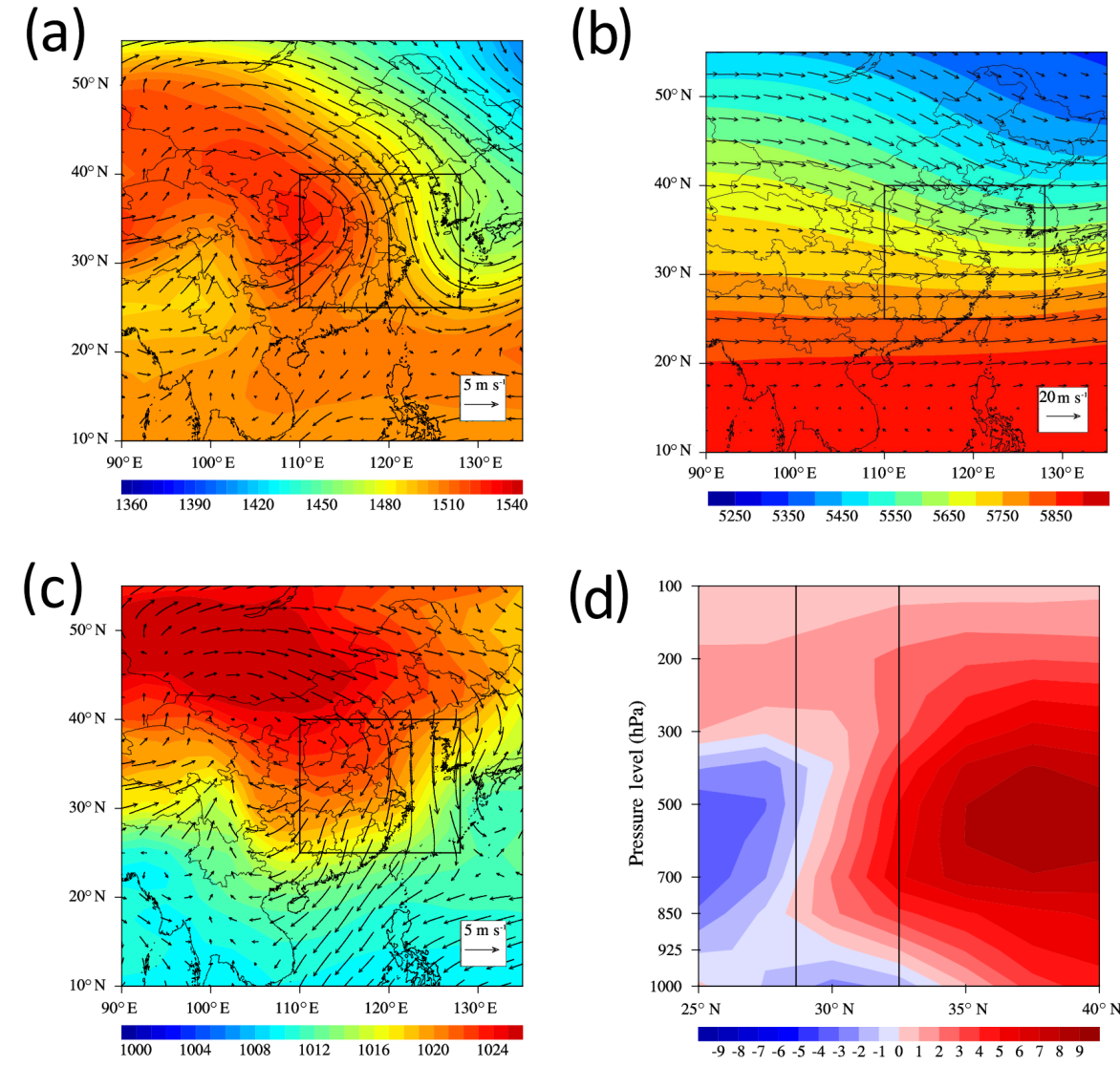

(d)
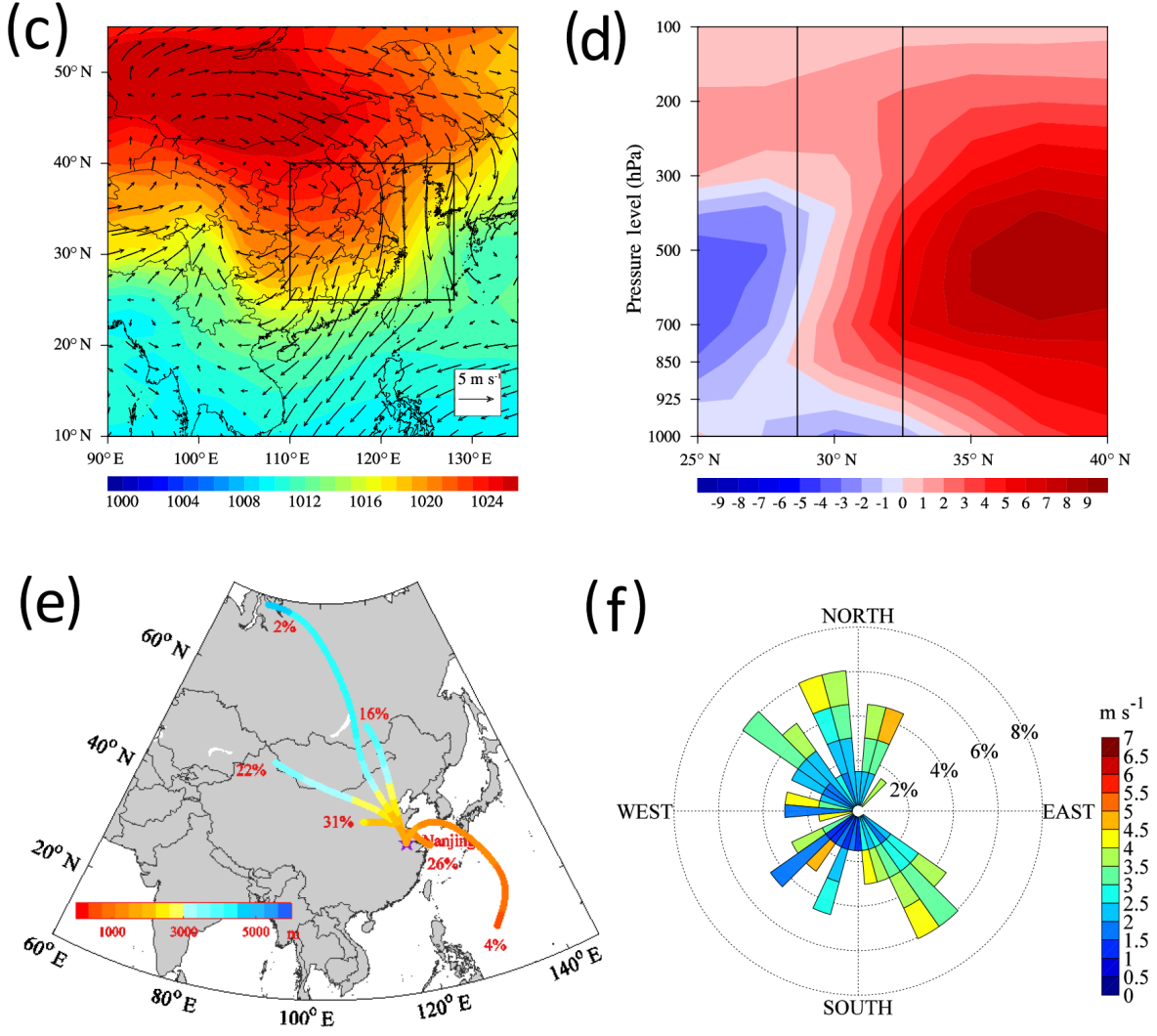

Figure 9. As in Fig. 7, but for Pattern 3.

flows from southern China meet with the southeast air flows from the East China Sea. After the convergence of these air masses, they jointly transport pollutants northwestward. In contrast, at the surface (Fig. 8c), the study area is located at the bottom of a high-pressure system and is impacted by a strong southeast wind. In the middle troposphere (Fig. 8b), the sparse isopleths indicate that there is a small geopotential height gradient, while the shallow ridge causes westerly flows. Figure 8e also illustrates these air pollutant transport paths. For the days when Pattern 2 is dominant, approximately $42 \%$ of the air masses are from the southwest and the south of China, and $15 \%$ are from the East China Sea. The air masses from the East China Sea are very important because the clean marine air masses may dilute the particle concentrations in the YRD. In addition, nearly $43 \%$ of air masses originate from the local sources of the YRD, which may be related to their short-range transport in the northwest direction. This is also in accordance with the dominant northwest surface wind in Nanjing (Fig. 8f). In regard to its vertical structure (Fig. 8d), Pattern 2 is obviously different than Pattern 1, as upward air flows are dominant to the south of $37.5^{\circ} \mathrm{N}$. The largest updraft zone $\left(\sim 7 \times 10^{-2} \mathrm{~Pa} \mathrm{~s}^{-1}\right)$ appears above the 

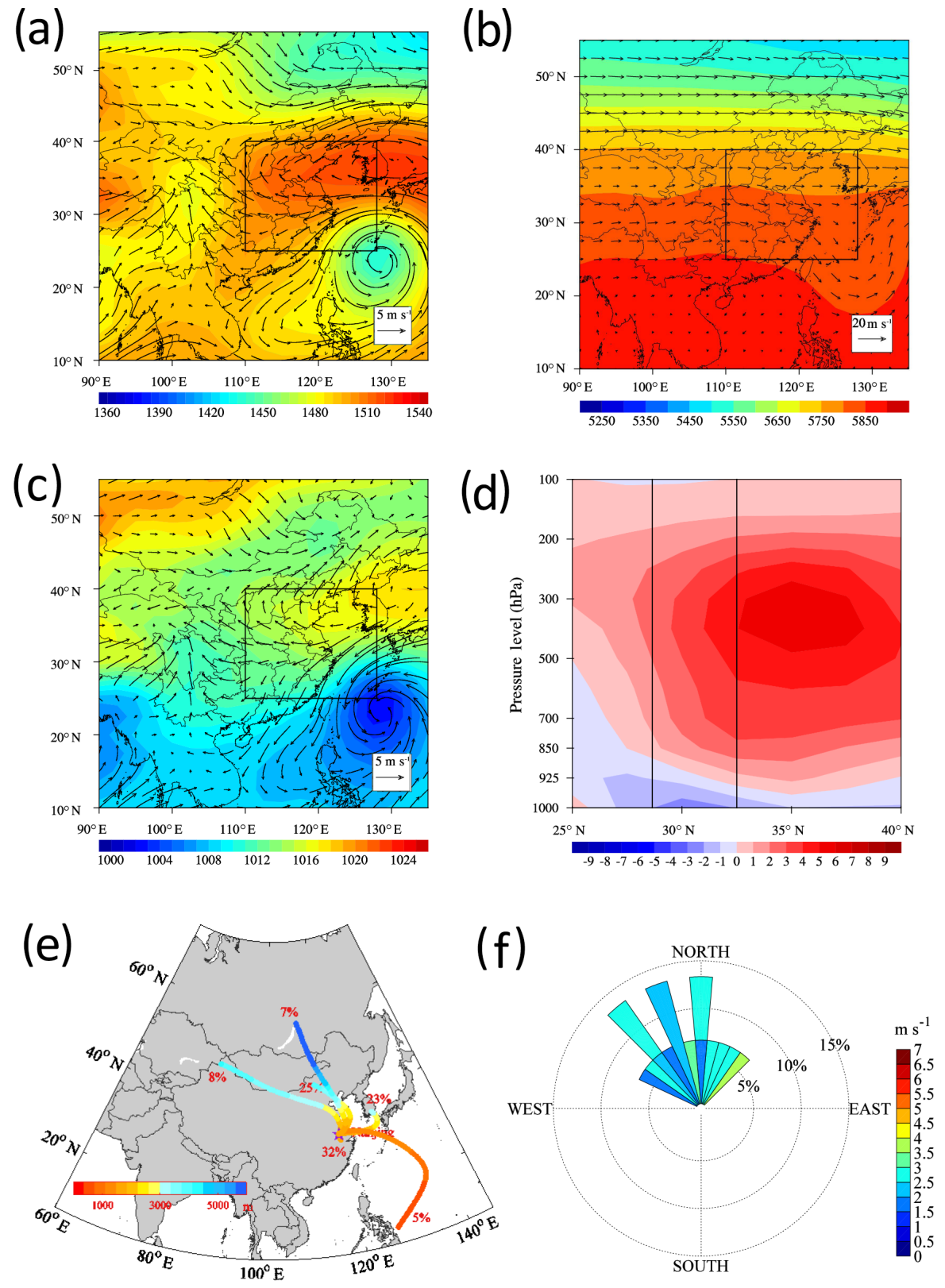

Figure 10. As in Fig. 7, but for Pattern 4.

YRD and between the altitudes of 700 and $500 \mathrm{hPa}$. The vertical velocity close to the surface is weaker than that at higher levels over the YRD. Meanwhile, stronger upward motion occurs near the surface at a latitude of $37.5^{\circ} \mathrm{N}$, with weak downward motion occurring above the $700 \mathrm{hPa}$ layer. The above discussion suggests that atmospheric pollutants in the YRD are horizontally transported northwestward to a higher latitude and vertically transported upward to higher layers. Therefore, despite the transport of abundant pollutants to the YRD via southwest air flows and the short-range northwest transport of polluted air masses, the strong surface southeast wind and upward motion under the weather situation of Pat- tern 2 result in much less particle pollution over the YRD compared to Pattern 1.

Pattern 3 tends to occur in winter $(36.4 \%$, as displayed in Table 3). Under this circumstance, the YRD is mainly controlled by a high-pressure system that is centered in central China (Fig. 9a). Meanwhile, northeastern China is under the steering influence of the northwest air flows at the rear of the East Asian major trough, with its trough axis appearing along the eastern coastline of China. Affected by the strong northwest winds coming from northern China, the polluted air masses from the BTH are easily transported to the YRD. At the higher layer of $500 \mathrm{hPa}$ (Fig. 9b), the circulation struc- 
(a)

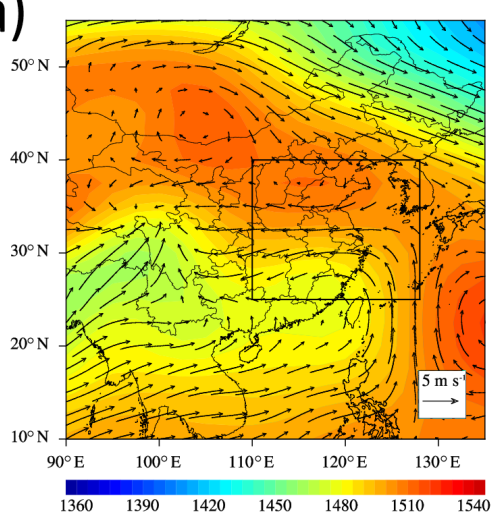

(c)

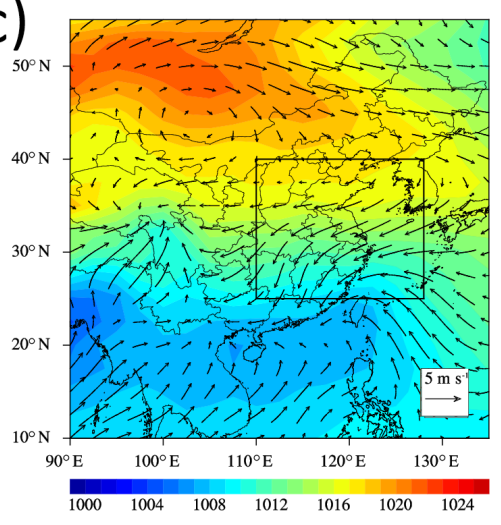

(e)

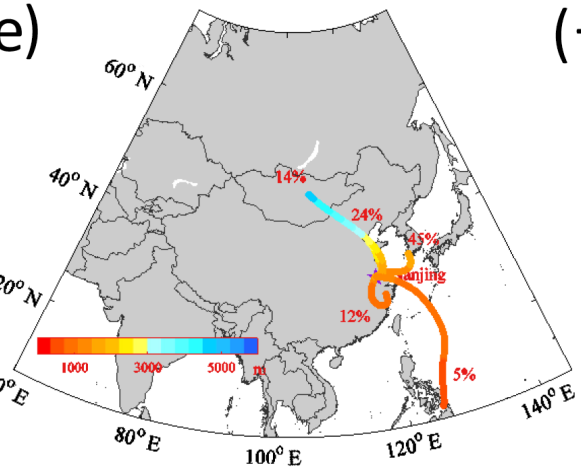

(b)

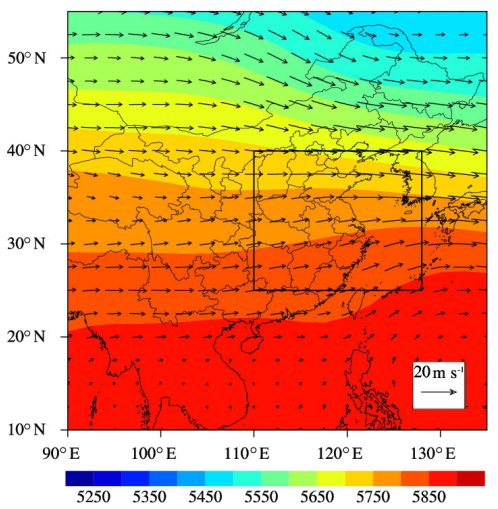

(d)

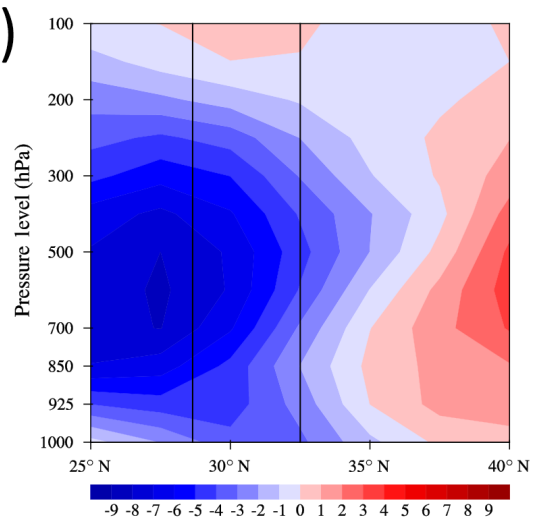

(f)

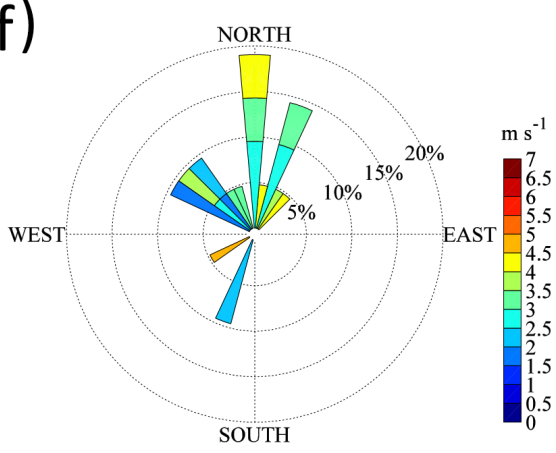

Figure 11. As in Fig. 7, but for Pattern 5.

ture patterns are similar to those of Pattern 1. A trough appears in the upper atmosphere, resulting in relatively strong west-northwest flows. The presence of dense isopleths indicates that there is a large geopotential height gradient and strong downward flows. At the surface layer (Fig. 9c), the presence of strong northerly wind is also evident, and the YRD is located at the bottom of a high-pressure system centered in the remote Mongolian region. The above discussion is further supported by the results of back trajectory calculations. As suggested in Fig. 9e, most air masses in clusters are from the Loess Plateau (31\%). The transport path of this cluster is relatively short, which may be attributed to its strong anti-cyclonic circulation. Due to the strong northerly wind, the long-range transport of air masses from remote Mongolia and northern China account for 22 and $18 \%$ of all trajectories, respectively. In addition, the local transport of air masses from the southeast coastal area in the YRD accounts for $26 \%$ of all trajectories, and the marine air masses cluster that originates from the western Pacific via the Yellow Sea accounts for $4 \%$ of all trajectories. For the vertical structure (Fig. 9d), the distribution of the vertical flow field is similar to that of Pattern 1, whereas the vertical wind 
is slightly stronger in the weather system of Pattern 3. Due to the influence of the high-pressure system, downward air flows are dominant to the north of approximately $28^{\circ} \mathrm{N}$ (including the YRD) below an altitude of $300 \mathrm{hPa}$. The largest descending velocity $\left(\sim 9 \times 10^{-2} \mathrm{~Pa} \mathrm{~s}^{-1}\right)$ also appears at an altitude of $500 \mathrm{hPa}$, covering the latitude of $35-40^{\circ} \mathrm{N}$. However, despite the higher surface pressure (Figs. 6i and 9c) and stronger downward motion (Fig. 9d), the surface wind is also much stronger for Pattern 3 (Figs. 6g, 9a and c), which alleviates the problems of air pollution over the YRD compared to Pattern 1. Overall, under the weather situation of Pattern 3 , the strong northwest wind in the front of the high-pressure system usually leads to the transport of polluted air masses from the BTH to the YRD. Nevertheless, the strong surface wind is conducive to the mitigation of pollutants, which plays a significant role in the level of air pollution over the YRD.

In Pattern 4, on both the surface and at the $850 \mathrm{hPa}$ level, the study area is under the control of a high-pressure system (Fig. 10a and c). The center of the high-pressure system is located in the Sea of Japan, while a cyclonic circulation occurs over the Philippine Sea. Anti-cyclonic circulation prevails over the YRD and horizontally brings the clean marine air masses to the land. Meanwhile, the sparse isopleths represent a small geopotential height gradient in the middle troposphere, which is accompanied by a much weaker west wind compared to the other patterns (Fig. 10b). Accordingly, influenced by the high-pressure system, downward atmospheric motion is clearly dominant in the vertical direction (Fig. 10d). The strongest downward motion $\left(\sim 6 \times 10^{-2} \mathrm{~Pa} \mathrm{~s}^{-1}\right)$ appears between the altitudes of 300 and $500 \mathrm{hPa}$ at a latitude of $35^{\circ} \mathrm{N}$. The weak updrafts near the surface may be related to the regional thermodynamic circulation. As shown in Fig. 10e, the cluster with the largest frequency of $32 \%$ represents the local transport of air masses from the southern adjacent areas in the YRD. Additionally, the air masses originating from northern China via Bohai Bay $(25 \%)$, from Japan via the Yellow Sea $(23 \%)$, and from the Philippines via the East China Sea $(5 \%)$ are also representative. In total, the clusters that pass over the ocean areas account for more than $50 \%$ of all trajectories. Therefore, under this weather situation, the dilution effects of clean marine air masses play a vital role in particle pollution over the YRD.

Pattern 5 features one of the most complex circulation situations at $850 \mathrm{hPa}$ (Fig. 11a). The YRD is located between the bottom of the northern high-pressure system and the top of the southern weak low-pressure system. Thus, the strong horizontal east wind prevails and easily carries clean marine air masses from the East China Sea to the YRD. The corresponding circulation structure at the surface layer is similar to that at the $850 \mathrm{hPa}$ layer (Fig. 11c), while east-northeast flows are prevalent over the study domain. In the upper troposphere, a ridge appears in the east due to the tropical cyclonic system, thus leading to the west-southwest flows over the region. Due to the abovementioned two opposite pressure systems (Fig. 11a), strong upward air flows are dominant to the south of the latitude of $35^{\circ} \mathrm{N}$, while downward motion is obvious in the north (Fig. 11d). The largest ascending velocity $\left(\sim-9 \times 10^{-2} \mathrm{~Pa} \mathrm{~s}^{-1}\right)$ appears at a latitude of approximately $27.5^{\circ} \mathrm{N}$ in the upper troposphere. This strong upward motion facilitates the diffusion and removal of the accumulated pollutants from the surface layer. According to Fig. 11e, the cluster with the largest frequency of $45 \%$ consists of the wet air parcels originating from Japan via the Yellow Sea. Only $5 \%$ of the trajectories originate from the Philippines and pass over the East China Sea. Overall, under the weather situation of Pattern 5, the transport of clean marine air masses and favorable diffusion conditions contribute to the good air quality over the YRD.

To summarize, the weather situations for Patterns 1-5 are more or less affected by a high-pressure system. However, the relative positions of the study area to the anti-cyclonic circulation system have significant effects on the air quality of the YRD. These differences determine the wind speed and wind direction, and the latter further determines whether the YRD is influenced by the clean marine air masses. In both Pattern 1 and Pattern 3, the YRD is impacted by the northwest air flows at the rear of the East Asian major trough, which transport abundant air pollutants from other regions (such as the BTH and the SCB) to the YRD and cause severe particle pollution (as well as high AOD values) in the YRD. In contrast, the weaker local surface wind in Pattern 1 is extremely conducive to the local accumulation of pollutants. For this reason, Pattern 1 is "the most polluted pattern", and it is responsible for most of the large-scale particle pollution episodes over the YRD. Due to its stronger surface wind, Pattern 3 is "the second-most polluted pattern". In Pattern 2, the polluted air masses mainly travel from the southern inland areas and synchronously meet with the clean marine air masses in the YRD. To some extent, this weather situation helps mitigate particle pollution in the YRD. In Pattern 4 and Pattern 5 , the YRD is directly influenced by air flows traveling from the ocean areas, and it is thus unlikely to be polluted. Thus, Pattern 4 and Pattern 5 can be identified as "the clean patterns". These data suggest that the clean marine air masses can substantially dilute the particle pollution over the YRD.

\section{Conclusions}

In this study, the spatial and temporal distributions of particle pollution in 16 YRD cities are characterized from December 2013 to November 2014. Meanwhile, synoptic weather classification is conducted to identify the dominant weather patterns over the YRD. The meteorological fields and $72 \mathrm{~h}$ backward trajectories are analyzed to reveal the potential impacts of weather systems on regional severe particle pollution episodes.

Observational records indicate that the concentrations of $\mathrm{PM}_{2.5}$ and $\mathrm{PM}_{10}$ decrease progressively in the northwestsoutheast direction. The pollution levels are comparatively 
higher in Jiangsu Province and much lower in the southeast coastal area (i.e., Ningbo, Taizhou, and Zhoushan). The highest particle concentrations occur in Nanjing, where the concentrations of $\mathrm{PM}_{2.5}$ and $\mathrm{PM}_{10}$ are 79 and $130 \mu \mathrm{g} \mathrm{m}^{-3}$, respectively. The $\mathrm{PM}_{2.5}: \mathrm{PM}_{10}$ ratios are high in the YRD, especially in winter. The seasonal mean $\mathrm{PM}_{2.5}: \mathrm{PM}_{10}$ ratios are 0.73 (winter), 0.61 (spring), 0.67 (summer), and 0.63 (autumn). These high $\mathrm{PM}_{2.5}: \mathrm{PM}_{10}$ ratios suggest that the $\mathrm{PM}_{2.5}$ fraction is extraordinarily dominant over the $\mathrm{PM}_{10}$ mass in the YRD. In addition, high AOD values are also found in the YRD, with an annual mean value of $0.71 \pm 0.57$ and a maximum seasonal mean value of $0.98 \pm 0.83$ in summer. The diurnal cycles of the particle concentrations in most cities follow the same pattern, reaching a morning peak from 08:00 to 12:00. There are three peaks in seasonal variations (December, March, and May or June). The wintertime peak is closely related to enhanced emissions during the heating season and poor meteorological conditions. Moreover, the YRD suffers from $\mathrm{PM}_{2.5}\left(\mathrm{PM}_{10}\right)$ pollution on nearly $28.0 \%(13.1 \%)$ of the days of the year. Continuous large-scale regional $\mathrm{PM}_{2.5}$ pollution episodes occur much more frequently than $\mathrm{PM}_{10}$ pollution episodes.

Based on the sums-of-squares technique, five typical synoptic weather patterns are objectively identified in the YRD, including Pattern 1 (northwesterly inland wind, which occurs on $47.7 \%$ of all days), Pattern 2 (southwesterly, $20.0 \%$ ), Pattern 3 (northerly inland wind, 18.1\%), Pattern 4 (cyclonerelated, $4.1 \%$ ), and Pattern 5 (oceanic-circulation-related, $5.8 \%$ ). Each pattern differs from the other in respect to the relative position of the YRD to the main synoptic system (the anti-cyclonic circulation system). This difference determines the wind speed and wind direction, which play important roles in the air quality level of the YRD. In particular, the wind direction is closely associated with determining whether the YRD is influenced by clean marine air masses. In the patterns in which the YRD is located at the rear of the East Asian major trough at $850 \mathrm{hPa}$ (Pattern 1 and Pattern 3), strong northwest wind can easily transport air pollutants from other polluted areas to the YRD, thus leading to serious particle pollution in the YRD. Due to the high-pressure system, significant vertical downward motion is dominant above the YRD, resulting in relatively stable weather conditions at the surface. With weak local surface wind, the worst polluted weather pattern (Pattern 1) features the highest regional mean $\mathrm{PM}_{10}\left(116.5 \pm 66.9 \mu \mathrm{g} \mathrm{m}^{-3}\right)$, $\mathrm{PM}_{2.5}\left(75.9 \pm 49.9 \mu \mathrm{g} \mathrm{m}^{-3}\right)$, and high AOD (0.74) values. Pattern 1 is also responsible for most of the large-scale regional $\mathrm{PM}_{2.5}(70.4 \%)$ and $\mathrm{PM}_{10}(78.3 \%)$ pollution episodes in the YRD. In Pattern 3, the strongest surface wind is conducive to the mitigation of pollution, thus resulting in the second-highest $\mathrm{PM}_{10}\left(86.9 \pm 49.5 \mu \mathrm{g} \mathrm{m}^{-3}\right)$ and $\mathrm{PM}_{2.5}$ $\left(59.1 \pm 37.3 \mathrm{\mu g} \mathrm{m}^{-3}\right)$ values. In contrast, under the weather system of other synoptic patterns (especially Pattern 4 and Pattern 5), the clean marine air masses, which are transported via the east-southeast wind, play a crucial role in the mitiga- tion of pollution over the YRD. Therefore, the YRD has a much smaller chance of being polluted.

In summary, the above results reveal that particle pollution in China is a thorny issue not only over a single city but also on a regional scale. This study can enhance our understanding of the features of particle pollution in East Asia. Meanwhile, these results also confirm that large-scale synoptic weather systems exert large impacts on regional particle pollution. Therefore, establishing potential links between different levels of particle pollution and predominant synoptic patterns can provide insight into formulating pollution control and mitigation strategies.

Data availability. The air quality monitoring records are available at http://106.37.208.233:20035. The meteorological data are available at http://www.nmc.cn. The MODIS/AOD records are available at https://ladsweb.modaps.eosdis.nasa.gov/search/. The NCEP reanalysis data are available at https://www.esrl.noaa.gov/psd/ data/gridded/data.ncep.reanalysis2.pressure.html and http://ready. arl.noaa.gov/archives.php (Kanamitsu et al., 2012).

Competing interests. The authors declare that they have no conflict of interest.

Special issue statement. This article is part of the special issue "Regional transport and transformation of air pollution in eastern China". It is not associated with a conference.

Acknowledgements. This work was supported by the National Natural Science Foundation of China (41475122, 91544230, 41621005), the National Key Research and Development Program of China (2016YFC0203303, 2016YFC0208504), the open research fund of the Chongqing Meteorological Bureau (KFJJ201607), and the Fundamental Research Funds for the Central Universities of China (020714380036). The authors would like to thank the anonymous reviewers for their constructive and valuable comments on this manuscript.

Edited by: Jianmin Chen

Reviewed by: two anonymous referees

\section{References}

Barry, R. G., Kiladis, G., and Bradley, R. S.: Synoptic climatology of the Western United States in relation to climatic fluctuations during the twentieth century, Int. J. Climatol., 1, 97-113, 1981.

Brook, R. D., Rajagopalan, S., Pope, C. A., Brook, J. R., Bhatnagar, A., Diez-Roux, A. V., Holguin, F., Hong, Y., Luepker, R. V., and Mittleman, M. A.: Particulate matter air pollution and cardiovascular disease, Circulation, 121, 2331-2378, 2010.

Buchanan, C., Beverland, I. J., and Heal, M. R.: The influence of weather-type and long-range transport on airborne particle con- 
centrations in Edinburgh, UK, Atmos. Environ., 36, 5343-5354, 2002.

Chan, C. K. and Yao, X.: Air pollution in mega cities in China, Atmos. Environ., 42, 1-42, 2008.

Chen, M. L., Mao, I. F., and Lin, I. K.: The PM 2.5 and PM 10 particles in urban areas of Taiwan, Sci. Total Environ., 226, 227235, 1999.

Cheng, Z., Jiang, J., Fajardo, O., Wang, S., and Hao, J.: Characteristics and health impacts of particulate matter pollution in China (2001-2011), Atmos. Environ., 65, 186-194, 2013.

Chuang, M.-T., Chiang, P.-C., Chan, C.-C., Wang, C.-F., Chang, E., and Lee, C.-T.: The effects of synoptical weather pattern and complex terrain on the formation of aerosol events in the Greater Taipei area, Sci. Total Environ., 399, 128-146, 2008.

Chu, D., Kaufman, Y., Ichoku, C., Remer, L., Tanré, D., and Holben, B.: Validation of MODIS aerosol optical depth retrieval over land, Geophys. Res. Lett., 29, 8007, https://doi.org/10.1029/2001GL013205, 2002.

Chu, D., Remer, L., Kaufman, Y., Schmid, B., Redemann, J., Knobelspiesse, K., Chern, J. D., Livingston, J., Russell, P., and Xiong, X.: Evaluation of aerosol properties over ocean from Moderate Resolution Imaging Spectroradiometer (MODIS) during ACE - Asia, J. Geophys. Res.-Atmos., 110, D07308, https://doi.org/10.1029/2004JD005208, 2005.

Chu, D. A., Kaufman, Y., Zibordi, G., Chern, J., Mao, J., Li, C., and Holben, B.: Global monitoring of air pollution over land from the Earth Observing System - Terra Moderate Resolution Imaging Spectroradiometer (MODIS), J. Geophys. Res.-Atmos., 108, 4661, https://doi.org/10.1029/2002JD003179, 2003.

Deng, J. J., Wang, T. J., Jiang, Z. Q., Xie, M., Zhang, R. J., Huang, X. X., and Zhu, J. L.: Characterization of visibility and its affecting factors over Nanjing, China, Atmos. Res., 101, 681-691, 2011.

Draxler, R. and Rolph, G.: HYSPLIT (HYbrid Single-Particle Lagrangian Integrated Trajectory), NOAA Air Resources Laboratory, College Park, MD, Model access via NOAA ARL READY Website, 2013.

El-Kadi, A. K. A. and Smithson, P. A.: Atmospheric classifications and synoptic climatology, Prog. Phys. Geog., 16, 432-455, 1992.

Feng, J., Hu, J., Xu, B., Hu, X., Sun, P., Han, W., Gu, Z., Yu, X., and $\mathrm{Wu}, \mathrm{M}$.: Characteristics and seasonal variation of organic matter in PM 2.5 at a regional background site of the Yangtze River Delta region, China, Atmos. Environ., 123, 288-297, 2015.

Flocas, H., Kelessis, A., Helmis, C., Petrakakis, M., Zoumakis, M., and Pappas, K.: Synoptic and local scale atmospheric circulation associated with air pollution episodes in an urban Mediterranean area, Theor. Appl. Climatol., 95, 265-277, 2009.

Fu, Q., Zhuang, G., Wang, J., Xu, C., Huang, K., Li, J., Hou, B., Lu, T., and Streets, D. G.: Mechanism of formation of the heaviest pollution episode ever recorded in the Yangtze River Delta, China, Atmos. Environ., 42, 2023-2036, 2008.

Fu, Q., Zhuang, G., Li, J., Huang, K., Wang, Q., Zhang, R., Fu, J., Lu, T., Chen, M., and Wang, Q.: Source, long-range transport, and characteristics of a heavy dust pollution event in Shanghai, J. Geophys. Res.-Atmos., 115, 6128-6128, 2010.

Fu, X., Wang, S. X., Cheng, Z., Xing, J., Zhao, B., Wang, J. D., and Hao, J. M.: Source, transport and impacts of a heavy dust event in the Yangtze River Delta, China, in 2011, Atmos. Chem. Phys., 14, 1239-1254, 2014.
Green, M. C., Chen, L. A., DuBois, D. W., and Molenar, J. V.: Fine particulate matter and visibility in the Lake Tahoe Basin: Chemical characterization, trends, and source apportionment, J. Air Waste Manage., 62, 953-965, 2012.

Grundstrom, M., Tang, L., Hallquist, M., Nguyen, H., Chen, D., and Pleijel, H.: Influence of atmospheric circulation patterns on urban air quality during the winter, Atmospheric Pollution Research, 6, 278-285, 2015.

He, K., Yang, F., Ma, Y., Zhang, Q., Yao, X., Chan, C. K., Cadle, S., Chan, T., and Mulawa, P.: The characteristics of PM 2.5 in Beijing, China, Atmos. Environ., 35, 4959-4970, 2001.

Ho, K. F., Lee, S. C., Chan, C. K., Yu, J. C., Chow, J. C., and Yao, X. H.: Characterization of chemical species in PM 2.5 and PM 10 aerosols in Hong Kong, Atmos. Environ., 37, 31-39, 2003.

Hsu, N., Jeong, M. J., Bettenhausen, C., Sayer, A., Hansell, R., Seftor, C., Huang, J., and Tsay, S. C.: Enhanced Deep Blue aerosol retrieval algorithm: The second generation, J. Geophys. Res.-Atmos., 118, 9296-9315, 2013.

Huang, K., Zhuang, G., Lin, Y., Fu, J. S., Wang, Q., Liu, T., Zhang, R., Jiang, Y., Deng, C., Fu, Q., Hsu, N. C., and Cao, B.: Typical types and formation mechanisms of haze in an Eastern Asia megacity, Shanghai, Atmos. Chem. Phys., 12, 105-124, https://doi.org/10.5194/acp-12-105-2012, 2012.

Huang, R. J., Zhang, Y., Bozzetti, C., Ho, K. F., Cao, J. J., Han, Y., Daellenbach, K. R., Slowik, J. G., Platt, S. M., and Canonaco, F.: High secondary aerosol contribution to particulate pollution during haze events in China, Nature, 514, 218-222, 2014.

Huang, X., Wang, T., Talbot, R., Xie, M., Mao, H., Li, S., Zhuang, B., Yang, X., Fu, C., and Zhu, J.: Temporal characteristics of atmospheric CO2 in urban Nanjing, China, Atmos. Res., 153, 437-450, 2015.

Ji, D., Wang, Y., Wang, L., Chen, L., Hu, B., Tang, G., Xin, J., Song, T., Wen, T., and Sun, Y.: Analysis of heavy pollution episodes in selected cities of northern China, Atmos. Environ., 50, 338-348, 2012.

Kanamitsu, M., Ebisuzaki, W., Woollen, J., Yang, S., Hnilo, J., Fiorino, M., and Potter, G.: NCEP-DOE AMIP-II reanalysis (R-2), B. Am. Meteorol. Soc., 83, 1631-1643, 2002.

Kappos, A. D., Bruckmann, P., Eikmann, T., Englert, N., Heinrich, U., Höppe, P., Koch, E., Krause, G. H., Kreyling, W. G., and Rauchfuss, K.: Health effects of particles in ambient air, Int. J. Hyg. Envir. Heal., 207, 399-407, 2004.

Kang, H., Zhu, B., Su, J., Wang, H., Zhang, Q., and Wang, F.: Analysis of a long-lasting haze episode in Nanjing, China, Atmos. Res., 120-121, 78-87, 2013.

Kaufman, Y. J., Tanré, D., and Boucher, O.: A satellite view of aerosols in the climate system, Nature, 419, 215-223, 2002.

Kim, S.-W., Yoon, S.-C., Kim, J., and Kim, S.-Y.: Seasonal and monthly variations of columnar aerosol optical properties over east Asia determined from multi-year MODIS, LIDAR, and AERONET Sun/sky radiometer measurements, Atmos. Environ., 41, 1634-1651, 2007.

Kirchhofer, W.: Classification of European $500 \mathrm{mb}$ patterns, Arbeitsbericht der Schweizerischen Meteorologischen Zentralanstalt, Geneva, 43 pp., 1973.

Kong, X., He, W., Qin, N., He, Q., Yang, B., Ouyang, H., Wang, Q., and $\mathrm{Xu}, \mathrm{F}$.: Comparison of transport pathways and potential sources of PM 10 in two cities around a large Chinese lake us- 
ing the modified trajectory analysis, Atmos. Res., 122, 284-297, 2013.

Kurokawa, J., Ohara, T., Morikawa, T., Hanayama, S., JanssensMaenhout, G., Fukui, T., Kawashima, K., and Akimoto, H.: Emissions of air pollutants and greenhouse gases over Asian regions during 2000-2008: Regional Emission inventory in ASia (REAS) version 2, Atmos. Chem. Phys., 13, 11019-11058, https://doi.org/10.5194/acp-13-11019-2013, 2013.

Li, L., Chen, C. H., Fu, J. S., Huang, C., Streets, D. G., Huang, H. Y., Zhang, G. F., Wang, Y. J., Jang, C. J., Wang, H. L., Chen, Y. R., and Fu, J. M.: Air quality and emissions in the Yangtze River Delta, China, Atmos. Chem. Phys., 11, 16211639, https://doi.org/10.5194/acp-11-1621-2011, 2011.

Li, Q., Zhang, R., and Wang, Y.: Interannual variation of the wintertime fog-haze days across central and eastern China and its relation with East Asian winter monsoon, Int. J. Climatol., 36, 346-354, 2016.

Malm, W. C., Sisler, J. F., Huffman, D., Eldred, R. A., and Cahill, T. A.: Spatial and seasonal trends in particle concentration and optical extinction in the United States, J. Geophys. Res.-Atmos., 99, 1347-1370, 1994.

Mcgowan, H. and Clark, A.: Identification of dust transport pathways from Lake Eyre, Australia using Hysplit, Atmos. Environ., 42, 6915-6925, 2008.

McGregor, G. and Bamzelis, D.: Synoptic typing and its application to the investigation of weather air pollution relationships, Birmingham, United Kingdom, Theor. Appl. Climatol., 51, 223-236, 1995.

Ming, L., Ling, J., Li, J., Fu, P., Yang, W., Di, L., Gan, Z., Wang, Z., and Li, X.: PM 2.5 in the Yangtze River Delta, China: Chemical compositions, seasonal variations, and regional pollution events, Environ. Pollut., 223, 200-212, https://doi.org/10.1016/j.envpol.2017.01.013, 2017.

Niu, F., Li, Z., Li, C., Lee, K. H., and Wang, M.: Increase of wintertime fog in China: Potential impacts of weakening of the Eastern Asian monsoon circulation and increasing aerosol loading, J. Geophys. Res.-Atmos., 115, D00K20, https://doi.org/10.1029/2009JD01348, 2010.

Oanh, N. T. K. and Leelasakultum, K.: Analysis of meteorology and emission in haze episode prevalence over mountain-bounded region for early warning, Sci. Total Environ., 409, 2261-2271, 2011.

Putaud, J.-P., Raes, F., Van Dingenen, R., Brüggemann, E., Facchini, M.-C., Decesari, S., Fuzzi, S., Gehrig, R., Hüglin, C., and Laj, P.: A European aerosol phenomenology - 2: chemical characteristics of particulate matter at kerbside, urban, rural and background sites in Europe, Atmos. Environ., 38, 2579-2595, 2004.

Remer, L. A., Tanre, D., Kaufman, Y. J., Ichoku, C., Mattoo, S., Levy, R., Chu, D. A., Holben, B., Dubovik, O., and Smirnov, A.: Validation of MODIS aerosol retrieval over ocean, Geophys. Res. Lett., 29, MOD3-1-MOD3-4, https://doi.org/10.1029/2001GL013204, 2002.

Remer, L. A., Kaufman, Y., Tanré, D., Mattoo, S., Chu, D., Martins, J. V., Li, R.-R., Ichoku, C., Levy, R., and Kleidman, R.: The MODIS aerosol algorithm, products, and validation, J. Atmos. Sci., 62, 947-973, 2005.

Rolph, G., Stein, A., and Stunder, B.: Real-time Environmental Applications and Display sYstem: READY,
Environmental Modelling \& Software, 95, 210-228, https://doi.org/10.1016/j.envsoft.2017.06.025, 2017.

Russo, A., Trigo, R. M., Martins, H., and Mendes, M. T.: $\mathrm{NO}_{2}$, $\mathrm{PM}_{10}$ and $\mathrm{O}_{3}$ urban concentrations and its association with circulation weather types in Portugal, Atmos. Environ., 89, 768-785, 2014.

Santurtún, A., González-Hidalgo, J. C., Sanchez-Lorenzo, A., and Zarrabeitia, M. T.: Surface ozone concentration trends and its relationship with weather types in Spain (2001-2010), Atmos. Environ., 101, 10-22, 2015.

Singh, A. and Dey, S.: Influence of aerosol composition on visibility in megacity Delhi, Atmos. Environ., 62, 367-373, 2012.

Shu, L., Xie, M., Wang, T., Gao, D., Chen, P., Han, Y., Li, S., Zhuang, B., and Li, M.: Integrated studies of a regional ozone pollution synthetically affected by subtropical high and typhoon system in the Yangtze River Delta region, China, Atmos. Chem. Phys., 16, 15801-15819, https://doi.org/10.5194/acp-16-158012016, 2016.

State Environmental Protection Administration of China: China National Environmental Protection Standard: Automated Methods for Ambient Air Quality Monitoring, China Environmental Science Press, Beijing, 2006.

Stein, A. F., Draxler, R. R., Rolph, G. D., Stunder, B. J. B., Cohen, M. D., and Ngan, F.: NOAA's HYSPLIT Atmospheric Transport and Dispersion Modeling System, B. Am. Meteorol. Soc., 96, 2059-2077, https://doi.org/10.1175/BAMS-D-14$00110.1,2015$.

Wang, J., Hu, Z., Chen, Y., Chen, Z., and Xu, S.: Contamination characteristics and possible sources of PM10 and PM2.5 in different functional areas of Shanghai, China, Atmos. Environ., 68, 221-229, 2013.

Wang, M., Cao, C., Li, G., and Singh, R. P.: Analysis of a severe prolonged regional haze episode in the Yangtze River Delta, China, Atmos. Environ., 102, 112-121, 2015.

Wang, Y., Stein, A. F., Draxler, R. R., Rosa, J. D. D. L., and Zhang, X.: Global sand and dust storms in 2008: Observation and HYSPLIT model verification, Atmos. Environ., 45, 6368-6381, 2011.

Wang, Y., Li, L., Chen, C., Huang, C., Huang, H., Feng, J., Wang, S., Wang, H., Zhang, G., and Zhou, M.: Source apportionment of fine particulate matter during autumn haze episodes in Shanghai, China, J. Geophys. Res.-Atmos., 119, 1903-1914, 2014.

Xie, M., Zhu, K., Wang, T., Yang, H., Zhuang, B., Li, S., Li, M., Zhu, X., and Ouyang, Y.: Application of photochemical indicators to evaluate ozone nonlinear chemistry and pollution control countermeasure in China, Atmos. Environ., 99, 466-473, 2014.

Xie, M., Liao, J., Wang, T., Zhu, K., Zhuang, B., Han, Y., Li, M., and Li, S.: Modeling of the anthropogenic heat flux and its effect on regional meteorology and air quality over the Yangtze River Delta region, China, Atmos. Chem. Phys., 16, 6071-6089, https://doi.org/10.5194/acp-16-6071-2016, 2016a.

Xie, M., Zhu, K., Wang, T., Chen, P., Han, Y., Li, S., Zhuang, B., and Shu, L.: Temporal characterization and regional contribution to $\mathrm{O}_{3}$ and $\mathrm{NO}_{x}$ at an urban and a suburban site in Nanjing, China, Sci. Total Environ., 551, 533-545, $2016 \mathrm{~b}$.

Xie, M., Zhu, K., Wang, T., Feng, W., Gao, D., Li, M., Li, S., Zhuang, B., Han, Y., Chen, P., and Liao, J.: Changes in regional meteorology induced by anthropogenic heat and their impacts on air quality in South China, Atmos. Chem. Phys., 16, 1501115031, https://doi.org/10.5194/acp-16-15011-2016, $2016 \mathrm{c}$. 
Xie, M., Shu, L., Wang, T.-j., Liu, Q., Gao, D., Li, S., Zhuang, B.1., Han, Y., Li, M.-m., and Chen, P.-1.: Natural emissions under future climate condition and their effects on surface ozone in the Yangtze River Delta region, China, Atmos. Environ., 150, 162$180,2017$.

Xu, J. S., Xu, H. H., Xiao, H., Tong, L., Snape, C. E., Wang, C. J., and He, J.: Aerosol composition and sources during high and low pollution periods in Ningbo, China, Atmos. Res., 178-179, 559-569, 2016.

Yan, X. Y., Ohara, T., and Akimoto, H.: Bottom-up estimate of biomass burning in mainland China, Atmos. Environ., 40, 52625273, 2006.

Yang, S., He, H., Lu, S., Chen, D., and Zhu, J.: Quantification of crop residue burning in the field and its influence on ambient air quality in Suqian, China, Atmos. Environ., 42, 1961-1969, 2008.

Yarnal, B.: A procedure for the classification of synoptic weather maps from gridded atmospheric pressure surface data, Comput. Geosci., 10, 397-410, 1984.

Young, D. E., Kim, H., Parworth, C., Zhou, S., Zhang, X., Cappa, C. D., Seco, R., Kim, S., and Zhang, Q.: Influences of emission sources and meteorology on aerosol chemistry in a polluted urban environment: results from DISCOVER-AQ California, Atmos. Chem. Phys., 16, 5427-5451, https://doi.org/10.5194/acp16-5427-2016, 2016.

Zhang, J. P., Zhu, T., Zhang, Q. H., Li, C. C., Shu, H. L., Ying, Y., Dai, Z. P., Wang, X., Liu, X. Y., Liang, A. M., Shen, H. X., and Yi, B. Q.: The impact of circulation patterns on regional transport pathways and air quality over Beijing and its surroundings, Atmos. Chem. Phys., 12, 5031-5053, https://doi.org/10.5194/acp12-5031-2012, 2012.

Zhang, Q., Quan, J., Tie, X., Li, X., Liu, Q., Gao, Y., and Zhao, D.: Effects of meteorology and secondary particle formation on visibility during heavy haze events in Beijing, China, Sci. Total Environ., 502C, 578-584, 2014.
Zhao, X. J., Zhao, P. S., Xu, J., Meng, W., Pu, W. W., Dong, F., He, D., and Shi, Q. F.: Analysis of a winter regional haze event and its formation mechanism in the North China Plain, Atmos. Chem. Phys., 13, 5685-5696, https://doi.org/10.5194/acp13-5685-2013, 2013.

Zheng, G. J., Duan, F. K., Su, H., Ma, Y. L., Cheng, Y., Zheng, B., Zhang, Q., Huang, T., Kimoto, T., Chang, D., Pöschl, U., Cheng, Y. F., and He, K. B.: Exploring the severe winter haze in Beijing: the impact of synoptic weather, regional transport and heterogeneous reactions, Atmos. Chem. Phys., 15, 2969-2983, https://doi.org/10.5194/acp-15-2969-2015, 2015a.

Zheng, X. Y., Fu, Y. F., Yang, Y. J., and Liu, G. S.: Impact of atmospheric circulations on aerosol distributions in autumn over eastern China: observational evidence, Atmos. Chem. Phys., 15, 12115-12138, https://doi.org/10.5194/acp-15-12115-2015, $2015 b$.

Zhu, J., Wang, T., Deng, J., Jiang, A., and Liu, D.: An emission inventory of air pollutants from crop residue burning in Yangtze River Delta Region and its application in simulation of a heavy haze weather process, Acta Scientiae Circumstantiae, 32, 30453055, 2012.

Zhu, K., Xie, M., Wang, T., Cai, J., Li, S., and Feng, W.: A modeling study on the effect of urban land surface forcing to regional meteorology and air quality over South China, Atmos. Environ., 152, 389-404, 2017.

Zhuang, G. S., Yuan, J. H., Yuan, H., and Zhao, C. Y.: The compositions, sources, and size distribution of the dust storm from China in spring of 2000 and its impact on the global environment, Science Bulletin, 46, 895-901, 2001. 